\title{
Natural approaches in metabolic syndrome management
}

\author{
Angelo Maria Patti ${ }^{1,2}$, Khalid Al-Rasadi ${ }^{3}$, Rosaria Vincenza Giglio ${ }^{1,2}$, Dragana Nikolic ${ }^{1,2}$, \\ Carlo Mannina ${ }^{1}$, Giuseppa Castellino ${ }^{1,2}$, Roberta Chianetta ${ }^{1,2}$, Maciej Banach ${ }^{4}$, Arrigo F.G. Cicero ${ }^{5}$, \\ Giuseppe Lippi ${ }^{6}$, Giuseppe Montalto ${ }^{1}$, Manfredi Rizzo ${ }^{1,2}$, Peter P. Toth ${ }^{7}$
}

\author{
${ }^{1}$ Biomedical Department of Internal Medicine and Medical Specialties, \\ University of Palermo, Italy \\ ${ }^{2}$ EuroMediterranean Institute of Science and Technology, Italy \\ ${ }^{3}$ Department of Clinical Biochemistry, Sultan Qaboos University, Muscat, Oman \\ ${ }^{4}$ Department of Hypertension, Chair of Nephrology and Hypertension, \\ Medical University of Lodz, Lodz, Poland \\ ${ }^{5}$ Department of Medical and Surgical Sciences, University of Bologna, Bologna, Italy \\ ${ }^{6}$ Section of Clinical Biochemistry, University of Verona, Verona, Italy \\ ${ }^{7} \mathrm{CGH}$ Medical Center, Sterling, Illinois; Ciccarone Center for the Prevention of \\ Cardiovascular Disease, Johns Hopkins University School of Medicine, Baltimore, \\ Maryland, USA
}

Submitted: 23 March 2017

Accepted: 26 March 2017

Arch Med Sci 2018; 14, 2: 422-441

DOI: https://doi.org/10.5114/aoms.2017.68717

Copyright $\odot 2017$ Termedia \& Banach

\section{Abstract}

Metabolic syndrome (MetS) is characterized as a group of cardiometabolic risk factors that raise the risk for heart disease and other health problems, such as diabetes mellitus and stroke. Treatment strategies include pharmacologic interventions and supplementary (or "alternative") treatments. Nutraceuticals are derived from food sources (isolated nutrients, dietary supplements and herbal products) that are purported to provide health benefits, in addition to providing basic nutritional value. Nutraceuticals are claimed to prevent chronic diseases, improve health, delay the aging process, increase life expectancy, and support the structure and function of the body. The study of the beneficial effects of nutraceuticals in patients with MetS, including product standardization, duration of supplementation and definition of optimal dosing, could help better define appropriate treatment. This review focuses on widely marketed nutraceuticals (namely polyphenols, omega-3 fatty acids, macroelements and vitamins) with clinically demonstrated effects on more than one component of MetS.

Key words: metabolic syndrome, vitamins, cardiovascular risk, macroelements, omega-3 fatty acids, polyphenols, nutraceuticals.

\section{Introduction}

Metabolic syndrome (MetS) is defined as the coexistence of risk factors of metabolic origin (insulin resistance, hyperinsulinemia, impaired glucose tolerance, type 2 diabetes mellitus, visceral obesity, atherogenic dyslipidaemia and/or, high blood pressure) that elevate risk for cardiovascular disease [1-3]. The most important components of MetS are related to each other: (1) obesity and lack of physical activity contribute to the development of insulin resistance, which is associated with increases in the concentration of triglycerides and low-density lipoprotein particles and decreases in high-density lipoprotein cholesterol (HDL-C), favoring the formation of atherosclerotic plaques, leading to coronary heart and

\author{
Corresponding author: \\ Manfredi Rizzo, MD, PhD \\ Biomedical Department \\ of Internal Medicine \\ and Medical Specialties \\ University of Palermo, \\ 141 Via del Vespro St \\ 90127 Palermo, Italy \\ Phone/fax: +39 (091) 6552945 \\ E-mail: manfredi.rizzo@ \\ unipa.it
}


cerebrovascular disease [4]; (2) insulin resistance contributes to higher levels of serum insulin and glucose, precursors to the development of diabetes mellitus [5]; (3) hyperinsulinemia results in excessive renal sodium retention and elevations in blood pressure [6]; (4) alteration of the intrinsic cellular expression of endothelial factors causes an increase in blood pressure associated with endothelial dysfunction and impaired generation of nitric oxide (NO) [7]. In addition to genetic predisposition, there are important environmental factors that can influence the pathogenesis of MetS; positive changes in lifestyle can beneficially impact all features of MetS [8].

The consumption of large quantities of fruits, vegetables, fish and dietary supplements are important for antioxidant and anti-inflammatory effects [9]. Currently, there is considerable interest in the favorable effect of antioxidants in fruits and vegetables on obesity and cardiovascular disease [10, 11]; noteworthy are also polyunsaturated fatty acids, which have a positive effect on hypertension, insulin resistance and triglycerides [12, 13]. An adequate intake of foods containing antioxidant compounds with an anti-inflammatory effect reduces the incidence of MetS [14] and the factors that determine this pathological condition [15-18].

\section{Effects of nutraceuticals on metabolic syndrome components}

\section{Abdominal obesity}

Green tea is a natural source of antioxidants in the form of catechins, particularly epigallocatechin gallate (EGCG) $[19,20]$. Flavonoids of this group inhibit the expression of inducible NO synthase that potentiates inflammation, platelet aggregation, and oxidative stress [19]. Experimentally drinking or eating green tea significantly reduces both body fat and body weight (BW) [21]. Obese hypertensive patients were treated for 3 months with extracts of green tea. The study group experienced a decrease in anthropometric parameters (BW from 73.2 to $71.9 \mathrm{~kg}, p<0.001$; body mass index (BMI) from 27.4 to $26.9 \mathrm{~kg} / \mathrm{m}^{2}, p<0.001$, and waist circumference from 95.8 to $91.5 \mathrm{~cm}, p<0.001$ ) [22].

The polyunsaturated omega- 3 fatty acids are important supplements, which include linolenic acid (ALA), eicosapentaenoic acid (EPA) and docosahexaenoic acid (DHA). These long chain fatty acids are not synthesized in the body, so they must be derived from exogenous sources such as marine fish. It is important to maintain a proper ratio of omega- 6 and omega-3 fatty acids [23]; research has shown that ALA has no effect on obesity, while EPA and DHA reduce adipose tissue mass [24], especially when combined with lifestyle modification interventions [25].
Resveratrol (3,5,4'-trihydroxy-trans-stilbene) is a natural polyphenol that is produced by grapes, peanuts, berries and Polygonum cuspidatum (Japanese knotweed) [26, 27]. A systematic review has shown that resveratrol does not consistently improve BMI or BW ( $p>0.05)$, fat mass, fat volume, or abdominal fat distribution $(p>0.05)$. Instead this polyphenol has been shown to have a significant positive effect $(p<0.05)$ on inflammatory markers [28].

Dinca et al. wanted to clarify the role of vitamin D supplementation on adipokines through a systematic review and meta-analysis of nine randomized placebo-controlled trials (RCTs) [29]. These investigators did not find a significant change in plasma concentrations of adiponectin and leptin after vitamin D supplementation. In meta-regression, changes in plasma leptin concentrations and in plasma concentrations of adiponectin following vitamin D supplementation were found to be independent of the duration of treatment [29].

Nimitphong et al. investigated the effects of vitamin D supplementation for 3 months on anthropometric measurements [30]. Forty-seven subjects with impaired fasting glucose (IFG) and/ or impaired glucose tolerance (IGT) were randomized into three groups: control $(n=18)$, vitamin $D_{2}$ $(20,000$ IU weekly, $n=19)$ or vitamin $\mathrm{D}_{3}(15,000 \mathrm{IU}$ weekly, $n=10)$. After 3 months, waist circumference (WC) had significantly decreased in subjects in the vitamin D supplementation group. BW $(p=0.05)$, systolic blood pressure (SBP, $p=0.05)$, BMI $(p=0.06)$, and HOMA-IR $(p=0.09)$ also decreased, but not significantly. Subjects with an increase of total 25(OH)D levels > $10 \mathrm{ng} / \mathrm{ml}$ (23 of 29 subjects) had significant reductions in HOMA-IR and an increase in disposition index [30].

Di Pierro et al. in a randomized, controlled study evaluated the tolerability and the efficacy of curcumin in overweight subjects with metabolic syndrome, with a focus on impaired glucose intolerance and android-type fat accumulation [31]. Curcumin is the major bioactive ingredient extracted from the rhizome of the plant Curcuma longa (turmeric). Forty-four subjects, selected among those who after 30 days of diet and intervention lifestyle had a weight loss $<2 \%$, were treated for 30 days with either daily treatment of a curcumin-based product or pure phosphatidylserine [31]. Curcumin administration increased weight loss from $1.88 \%$ to $4.91 \%$, enhanced percentage reduction of body fat (from $0.70 \%$ to $8.43 \%$ ), increased waistline reduction (from $2.36 \%$ to $4.14 \%)$, improved hip circumference reduction from $0.74 \%$ to $2.51 \%$, and enhanced reduction of BMI (from $2.10 \%$ to $6.43 \%$ ) ( $p<0.01$ for all comparisons) [31]. The impact of a natural supplement (Kepar; Rikrea, Italy), containing several plant ex- 
tracts such as curcuma longa, silymarin, guggul, chlorogenic acid, and inulin, was evaluated in 78 patients with metabolic syndrome (MetS; 45 men; age: $62 \pm 9$ years) [18]. Kepar at a dose of 2 pills/day was given for 4 months as add-on therapy to the ongoing treatment, maintained at fixed doses for the entire study; after 4 months the investigators found significant reductions in BW (from $81.1 \pm 13.5$ to $79.4 \pm 12.5 \mathrm{~kg}, p<0.0001$ ), BMI (from $29.6(23.7)$ to $29.3(21.9) \mathrm{kg} / \mathrm{m}^{2}, p=$ 0.001 ), and WC (from $105 \pm 11$ to $102 \pm 10 \mathrm{~cm}$, $p=0.0004$ ), as well as in fasting glucose (from 6.5 (11.7) to $6.4(7.6) \mathrm{mmol} / \mathrm{l}, p=0.014)$ and total cholesterol (TC) (from $4.8 \pm 1.4$ to $4.5 \pm 1.0 \mathrm{mmol} /$, $p=0.03$ ). No significant changes were found in the other appraised parameters, including oxidative stress [18].

\section{Blood pressure}

Pomegranate has been widely used as a folk medicine in many cultures [32]. The content of soluble polyphenols in pomegranate juice $(\mathrm{PJ})$ varies within the limits of $0.2-1.0 \%$, and they include tannins, ellagic tannins, anthocyanins, catechins, as well as gallic and ellagic acids [33, 34]. The consumption of $\mathrm{PJ}$ reduces blood pressure, and in hypertensive patients affects the activity of angiotensin-converting enzyme (ACE) [35]. Aviram et al. noted a $36 \%$ decrease in serum ACE activity and a $5 \%$ reduction in systolic blood pressure [36]. The PJ has also been shown to beneficially impact oxidative stress [36, 37].

When measured over 8 weeks of treatment, green tea also lowers systolic blood pressure (from $126.2 \mathrm{~mm} \mathrm{Hg}$ to $118.6 \mathrm{~mm} \mathrm{Hg} ; p<0.05$ ) [21]. In another study in obese persons, green tea reduced blood pressure (SBP from $145 \pm 10 \mathrm{~mm} \mathrm{Hg}$ to $141 \pm 8 \mathrm{~mm} \mathrm{Hg}, p=0.004$; DBP from $88 \pm 4 \mathrm{~mm} \mathrm{Hg}$ to $84 \pm 3 \mathrm{~mm} \mathrm{Hg}, p<0.01)$ and the insulin level and improved the lipid profile $(p<0.05)$ [38].

The pro-health properties of garlic (Allium sativum) are due to its chemical composition [39, 40]. High levels of allicin and sulfur reduce blood pressure [41]. Data from clinical studies indicate that garlic powder is an antihypertensive agent in patients with hypertension and reduces both systolic (aged garlic extract $\Delta:-2.59 \pm 1.91$ vs. placebo, $\Delta:-1.72 \pm 1.60$ ) and diastolic (aged garlic extract $\Delta:-1.07 \pm 1.32$ vs. placebo, $\Delta:-0.31 \pm 1.17$ ) blood pressure [42]. The above results demonstrate that garlic as a food supplement may be useful in the treatment of MetS [43].

ALA, EPA and DHA also impact systolic and diastolic blood pressure in hypertensive patients. It has been suggested that the hypotensive properties of omega- 3 fatty acids are associated with angiotensin II antagonism and increased production of NO $[44,45]$.
Quercetin, the most abundant dietary flavonol, has antioxidant effects in cardiovascular disease. Quercetin protects against lipid peroxidation and reduces the cytokine-induced cell-surface expression of vascular cell adhesion molecule-1 (VCAM-1) and E-selectin, but the evidence regarding its effects on blood pressure (BP) has not been conclusive [46]. Serban et al. assessed the impact of quercetin on BP through a systematic review and meta-analysis of 7 available randomized controlled trials; the results of this meta-analysis showed significant reductions in both systolic BP $(-3.04 \mathrm{~mm} \mathrm{Hg}, p=0.028)$ and diastolic BP $(-2.63 \mathrm{~mm} \mathrm{Hg}, p<0.001)$ following supplementation with this compound [47]. When the studies were categorized according to quercetin dose, there was a significant systolic and diastolic BP-reducing effect in randomized controlled trials with doses $\geq 500 \mathrm{mg} /$ day $(-4.45 \mathrm{~mm} \mathrm{Hg}, p=0.007$ and $-2.98 \mathrm{~mm} \mathrm{Hg}, p<0.001$, respectively), and lack of a significant effect for doses < $500 \mathrm{mg} /$ day, but indirect comparison tests failed to demonstrate significant differences between doses [47].

The International Study of Macro- and MicroNutrients and Blood Pressure is a cross-sectional epidemiologic study of 4680 men and women aged 40 to 59 from 17 population samples in Japan, China, the United Kingdom, and the United States [48]. The results indicate the potential for increased phosphorus/mineral intake to lower blood pressure as part of the recommendations for healthier eating patterns for the prevention and control of prehypertension and hypertension [48]. Dietary calcium and magnesium, correlated with phosphorus intake (partial $r=0.71$ and $r=0.68$ ), were inversely associated with blood pressure; blood pressures were lower by $1.9 \mathrm{~mm} \mathrm{Hg}$ to $4.2 \mathrm{~mm} \mathrm{Hg}$ systolic/1.2 $\mathrm{mm} \mathrm{Hg}$ to $2.4 \mathrm{~mm} \mathrm{Hg}$ diastolic for people with intakes above versus below country-specific medians for all 3 of the minerals [48].

\section{Glycemic and lipid metabolic disorders}

Green tea consumption is known to be associated with enhanced cardiovascular and metabolic health [19, 21]. Supplementation with green tea extract results in significant reductions in TC (from $5.4 \pm 1.0 \mathrm{mmol}$ to $5.0 \pm 0.9 \mathrm{mmol} ; p=$ 0.009), low-density lipoprotein cholesterol (LDL-C) (from $3.5 \pm 1.0 \mathrm{mmol}$ to $3.1 \pm 0.9 \mathrm{mmol} ; p=0.011$ ) and triglyceride (TG) (from $1.4 \pm 0.6 \mathrm{mmol}$ to 1.1 $\pm 0.5 \mathrm{mmol} ; p=0.004$ ), and an increase in highdensity lipoprotein (HDL-C) (from $1.2 \pm 0.2 \mathrm{mmol}$ to $1.4 \pm 0.3 \mathrm{mmol} ; p<0.001$ ) [21].

Rebello et al. examined the effects of a gastrointestinal microbiome modulator (GIMM) containing inulin, $\beta$-glucan, blueberry anthocyanins, and blueberry polyphenols on metabolic parameters, 
fecal markers of gut microbiota, and satiety in 30 overweight or obese individuals aged 18 to 70 years [49]. After 4 weeks GIMM consumption improved blood glucose tolerance $(p=0.008)$, and the desire to eat was reduced $(p=0.03)$ compared to the placebo. There were no statistically significant differences in insulin sensitivity, fecal markers of gut microbiota, or serum lipid concentrations between the groups. However, plasma ghrelin concentrations significantly decreased in the GIMM group $(-13.4 \pm 72.5, p=0.03)$ compared to the placebo [49].

Chokeberry is a shrub deciduous tree belonging to the Rosaceae family in North America [26]. Aronia berries among all known fruits are distinguished by the highest antioxidant content. They are rich in polyphenols and anthocyanins, including flavonols, especially quercetin and kaempferol and the cyanidin glycosides. Aronia fruit contains organic acids, vitamin C, sugars, pectin, carotene, tannin and inorganic compounds including boron, fluorine, manganese, molybdenum, iodine and iron [27]. Broncel et al. detected beneficial effects of anthocyanins on metabolic parameters in 22 healthy volunteers and 25 patients with MetS treated with anthocyanins $(3 \times 100 \mathrm{mg} /$ day $)$ for 2 months. After 2 months of treatment a significant reduction in TC from $242.80 \pm 34.48$ to 227.96 $\pm 33.07 \mathrm{mg} / \mathrm{dl}(p<0.001)$, LDL-C from 158.71 \pm 35.78 to $146.21 \pm 34.63 \mathrm{mg} / \mathrm{dl}(p<0.01)$ and triglycerides from $215.92 \pm 63.61$ to $187.58 \pm 90 \mathrm{mg} / \mathrm{dl}$ ( $p<0.05$ ) was observed, but fasting blood glucose levels did not change significantly [50].

White mulberry (Morus alba) is a plant traditionally grown in China, Korea, and Japan [51]. Mulberry leaf extract lowers postprandial glucose; this is due to the fact that it is rich in DNJ (1,5-dideoxy-1,5-imino-D-sorbitol), which is an inhibitor of $\alpha$-glucosidase. DNJ inhibits $\alpha$-glucosidase in the small intestine by binding to its active site [51]. An open-label, single-group study was conducted in 10 subjects with initial serum TG level $\geq 200 \mathrm{mg}$ / $\mathrm{dl}$; subjects ingested capsules containing DNJ-rich mulberry leaf extract at $12 \mathrm{mg}$ three times daily before meals for 12 weeks [52]. White mulberry extract had a significant impact on the changes in the concentration of LDL-C (large LDL-C from baseline $18.1 \pm 5.2$ to $20.7 \pm 4.7 \mathrm{mg} / \mathrm{dl}$ at week 12 , $p=0.047$; medium LDL-C from baseline $32.8 \pm 8.9$ to $43.4 \pm 9.3 \mathrm{mg} / \mathrm{dl}$ at week $12, p<0.001$; small LDL-C from baseline $28.7 \pm 7.1$ to $36.2 \pm 6.9 \mathrm{mg} / \mathrm{dl}$ at weeks $12 ; p=0.005$ ) and HDL-C (mean particle size was from baseline $10.40 \pm 0.18 \mathrm{~nm}$ to 10.54 $\pm 0.19 \mathrm{~nm}$ at week $12, p=0.006)$ subfractions and TG $(312 \pm 90 \mathrm{mg} / \mathrm{dl}$ at baseline to $252 \pm 78 \mathrm{mg} / \mathrm{dl}$ at week $12, p=0.058$ ) [52]. LDL size is an important predictor of $C V$ events and progression of CAD and evidence suggests that both quality (particu- larly small, dense $\mathrm{LDL}$ ) and quantity may increase CV risk [16, 53, 54]. A predominance of small, dense LDL particles (LDL-3 to -7) has been recognized as an emerging CV risk factor by the National Cholesterol Education Program Adult Treatment Panel III [2, 3].

In recent studies Citrus bergamia (known as Bergamot) juice was shown to reduce serum lipid levels, and this benefit can be attributed to high amounts of flavonoids in bergamot juice (neoeriocitrin, neohesperidin, naringin) [15]. Toth et al. investigated the effects of bergamot extract on cardio-metabolic parameters, including plasma lipids, atherogenic lipoproteins and subclinical atherosclerosis [17]. After 6 months of administration bergamot had significantly modified lipids (TC from $6.6 \pm 0.4 \mathrm{mmol} / /$ to $5.8 \pm 1.1 \mathrm{mmol} / \mathrm{l}$, $p<0.0001$; TG from $1.8 \pm 0.6 \mathrm{mmol} / /$ to $1.5 \pm 0.9$ $\mathrm{mmol} / \mathrm{l}, p=0.0020$; LDL-C from $4.6 \pm 0.2 \mathrm{mmol} / \mathrm{l}$ to $3.7 \pm 1.0 \mathrm{mmol} / \mathrm{l}, p<0.0001$; HDL-C increased from $1.3 \pm 0.2 \mathrm{mmol} / \mathrm{l}$ to $1.4 \pm 0.4 \mathrm{mmol} / \mathrm{l}, p<$ $0.0007)$, LDL-C subfractions (LDL-1 from 41.2 $\pm 0.2 \%$ to $49.6 \pm 0.2 \%, p<0.0001$; LDL-3, LDL-4 and LDL-5 particles from $14.5 \pm 0.1 \%$ to $9.0 \pm 0.1 \%$, $p<0.0001 ; 3.2 \pm 0.1 \%$ to $1.5 \pm 0.1 \%, p=0.0053$; $0.3 \pm 0.0 \%$ to $0.1 \pm 0.0 \%, p=0.0133$, respectively) and carotid intima-media thickness (cIMT) (from $1.2 \pm 0.4 \mathrm{~mm}$ to $0.9 \pm 0.1 \mathrm{~mm} ; p<0.0001$ ) in patients with moderate hypercholesterolemia [17].

Ginseng extract obtained from roots, fruits and leaves of American ginseng (Panax quinquefolium) or Asian ginseng (Panax ginseng) has been widely studied for the treatment of diabetes, dyslipidaemia, and obesity. It contains many bioactive compounds, ginsenosides (such as Rb1, Rb2, Rc, Rd, Re and Rg1; this classification depends on their $\mathrm{Rf}$ values (from small to large) in thin-layer chromatography [55]), which contribute to the regulation of glucose levels and blood pressure [56]. One report showed that administration of ginseng elevated mood, improved psychophysical and physical performance, and reduced fasting blood glucose (FBG), hemoglobin $\mathrm{A}_{1 \mathrm{c}}\left(\mathrm{HbA}_{1 \mathrm{c}}\right)$ and body weight in diabetic patients [57]. In addition to glucose metabolism, ginseng has also been shown to regulate lipid metabolism. In one study, ginseng was administered through a diet supplement; ginseng treatment lowered serum TC $(67-83 \%$ of control, $p<0.01)$ and LDL-C (53-81\% of control, $p<0.01)$. The decrease in TC and LDL-C was related to the suppression of $\beta$-hydroxy- $\beta$-methylglutaryl-CoA (HMG-CoA) reductase and in parallel of cholesterol $7 \alpha$-hydroxylase activity [58]. Cholesterol $7 \alpha$-hydroxylase (Cyp7a1) catalyzes the rate-limiting step in the intrahepatic conversion of cholesterol to bile acids. When $7 \alpha$-hydroxylase activity is suppressed, decreased bile acid biosynthesis leads to an increased hepatic cholesteryl 
ester content, increased hepatic expression of $A B C A 1$, and an increased hepatic cholesterol efflux to $\mathrm{HDL}$, resulting in increased plasma HDL-C levels [59]. Some clinical studies have suggested that ginseng increases the secretion of insulin [56]. This stimulation of insulin secretion may be due to the following factors: (1) biosynthesis of insulin is increased significantly in pancreatic islets by ginseng extract DPG-3-2 (a component of ginseng radix) in vivo and in vitro [60]; (2) release of insulin is increased by the ginsenoside Rh2. This mechanism is related to the release of acetylcholine from nerve terminals in pancreases and stimulation of muscarinic $M(3)$ receptors in $\beta$-cells $[61,62]$; and (3) ginseng may prevent $\beta$-cell apoptosis [63]. Various ginsenosides have been shown to upregulate insulin and non-insulin stimulated glucose transport in different animal models and cell lines. Direct clinical investigations of insulin sensitivity using the euglycemic-hyperinsulinemic clamp are needed to confirm this mechanism [64]. Green tea extract increases the levels of glutathione in the blood and plasma total antioxidant capacity in patients with MetS [58].

To date it is not clear how the omega- 3 fatty acids reduce the risk of cardiovascular disease. They do improve the lipid profile with a decrease in TC, LDL-C, and TG and an increase in HDL-C [65]. The efficacy of icosapent ethyl (IPE; Vascepa [formerly AMR101]; Amarin Pharma Inc., Bedminster, NJ, USA) in improving lipid parameters was demonstrated in a 12-week randomized, placebo-controlled trial (ANCHOR) that enrolled statin-treated patients at high cardiovascular risk with well-controlled LDL-C levels and persistently high TG levels (at or above $200 \mathrm{mg} / \mathrm{dl}$ and less than $500 \mathrm{mg} / \mathrm{dl}$ ) [66]. Compared with placebo, IPE $4 \mathrm{~g} /$ day and $2 \mathrm{~g} /$ day reduced median TG levels from baseline by $21.5 \%(p<0.0001)$ and $10.1 \%(p=0.0005)$, respectively, without increasing LDL-C levels. The $4 \mathrm{~g} /$ day dose decreased LDL-C levels by $6.2 \%$ ( $p=0.007)$ and significantly reduced other lipid parameters, compared with a light liquid paraffin placebo, including apolipoprotein B (9.3\%; $p<0.0001)$, very-low-density lipoprotein cholesterol (24.4\%; $p<0.0001)$, lipoprotein-associated phospholipase A2 (19.0\%; $p<0.0001)$, and high-sensitivity C-reactive protein (hs-CRP) (22.0\%; $p=0.0005$ ) [66]. In 1999 and 2007, two major outcome trials of cardiovascular disease documented the efficacy of omega- 3 fatty acids in the primary and secondary prevention of coronary heart disease (CHD). The Italian Group for the Study of the Survival of Myocardial Infarction (GISSI)-Prevention study was a secondary outcomes study in which 11,324 post-myocardial infarction (MI) patients were randomly assigned to receive a fish oil supplement $(0.85 \mathrm{~g}$ of eicosapentaenoic acid
(EPA) plus docosahexaenoic acid (DHA)), $0.3 \mathrm{~g}$ of vitamin E, both, or none [67]. Patients taking omega-3 fatty acids, but not vitamin $E$, had a $15 \%$ reduction $(p=0.02)$ in the primary endpoint (death, nonfatal MI, and stroke), including 20\% and 30\% decreases in total and cardiovascular mortality, respectively [67]. In the Japan Eicosapentaenoic Acid (EPA) Lipid Intervention Study (JELIS), 18,645 patients with hypercholesterolemia (80\% in primary and $20 \%$ in secondary prevention) received statins alone or in combination with highly purified EPA (1.8 g/day) [68]. Although this study was limited to Japanese patients, most of whom were postmenopausal women, after 5 years patients receiving the combined treatment experienced a $19 \%$ relative reduction in major coronary events $(p=0.01)$ [68]. Beneficial effects were noted in both primary and secondary prevention subgroups, but these were significant only in the secondary prevention subgroup (8.7\% in the EPA group vs. $10.7 \%$ in the control group; $p=0.048)$. In patients with TG $>200 \mathrm{mg} / \mathrm{dl}(>2.3 \mathrm{mmol} / \mathrm{l})$ and $\mathrm{HDL}-\mathrm{C}<40 \mathrm{mg} / \mathrm{dl}$ (< $1.0 \mathrm{mmol} / \mathrm{l})$, risk reduction was $53 \%$ compared with statin monotherapy [68]. The Reduction of Cardiovascular Events with EPA - Intervention Trial (REDUCE-IT; NCT01492361) [69] and the STatin Residual risk reduction with EpaNova in hiGh cardiovascular risk paTients with Hypertriglyceridemia (STRENGTH; NCT02104817) trial [70] are currently under way. These studies should provide valuable information on the utility of omega-3 fatty acids in combination with statin therapy in high-risk patients with TG levels of $200-500 \mathrm{mg} / \mathrm{dl}$ [71].

Considerable controversy exists regarding the association of omega-3 polyunsaturated fatty acids (PUFAs) and major cardiovascular end points. Some primary and secondary prevention trials suggest that there is no benefit to omega- 3 PUFA supplementation in the prevention of CVD [72]. Fourteen randomized controlled trials (RCTs) $(20,485$ subjects enrolled, mean age of participants was 63.4 years and $79 \%$ were male) were included in a meta-analysis. Included patient groups were those with stable coronary heart disease, recent myocardial infarction, implanted cardioverter defibrillators, congestive heart failure and other cardiovascular diseases. Daily doses of eicosapentaenoic acid or docosahexaenoic acid ranged from $0.4 \mathrm{~g}$ to $4.8 \mathrm{~g}$. Follow-up ranged from 1 to 5 years. Placebo groups received vegetable oils, mixed fatty oil and other "inert" or poorly defined substances [73]. Omega-3 fatty acid supplementation did not reduce the risk of overall cardiovascular events $(\mathrm{RR}=0.99,95 \% \mathrm{Cl}$ : 0.89-1.09; 14 RCTs), risk of all-cause mortality (13 RCTs), sudden cardiac death (5 RCTs), myocardial infarction (11 RCTs), fatal myocardial infarction (5 RCTs), nonfatal myocardial infarction 
(7 RCTs), angina and unstable angina (7 RCTs), congestive heart failure (6 RCTs) or transient ischaemic attack and stroke (seven RCTs) [73]. There was a significant reduction in cardiovascular death ( $R R=0.91,95 \% \mathrm{Cl}: 0.84-0.99 ; 11$ RCTs), which became non-significant when a study with a significant baseline imbalance (for history of angina) was removed. No significant preventive effect was observed in any of the subgroup analyses [73]. Another meta-analysis included 20 randomized controlled trials (68,680 participants, average age 68 years) that compared omega- 3 polyunsaturated fatty acid supplementation against other diet or placebo for the prevention of primary or secondary cardiovascular disease in adults [74]. There were no statistically significant associations between omega-3 PUFA supplementation and all-cause mortality (RR $=0.96,95 \% \mathrm{Cl}$ : $0.91-$ $1.02 ; 17$ RCTs), cardiac death $(\mathrm{RR}=0.91,95 \% \mathrm{Cl}$ : 0.85-0.98; 13 RCTs), sudden death ( $R R=0.87$, 95\% Cl: 0.75-1.01; 7 RCTs), myocardial infarction $(\mathrm{RR}=0.89,95 \% \mathrm{Cl}: 0.76-1.04 ; 13 \mathrm{RCTs})$ or stroke $(\mathrm{RR}=1.05,95 \% \mathrm{Cl}:$ 0.93-1.18; 9 RCTs). Results for absolute risk reductions were not statistically significant. Subgroup analyses did not alter the main findings. Omega-3 PUFA supplementation was not associated with a lower risk of all-cause mortality, cardiac death, sudden death, myocardial infarction or stroke [74].

Vitamin E, a predominant antioxidant present in the LDL particle, blocks the chain reaction of lipid peroxidation by scavenging intermediate peroxyl radicals [75]. The data on the reduction of cardiovascular risk using vitamin $\mathrm{E}$ are conflicting, with most studies showing no benefit except in very specific subpopulations. According to a twoby-two factorial design, 2545 women and 6996 men 55 years of age or older, who were at high risk for cardiovascular events because they had cardiovascular disease or diabetes in addition to one other risk factor, received either $400 \mathrm{IU}$ of vitamin E daily from natural sources or matching placebo and either an angiotensin-converting-enzyme inhibitor (ramipril) or matching placebo for a mean of 4.5 years [76]. The primary outcome was a composite of myocardial infarction, stroke, and death from cardiovascular causes. The secondary outcomes included unstable angina, congestive heart failure, revascularization or amputation, death from any cause, complications of diabetes, and cancer [76]. Seven hundred and seventy-two patients assigned to vitamin $E$ (16.2\%) and 739 to placebo (15.5\%) had a primary outcome event $(R R=1.05,95 \% \mathrm{Cl}$ : 0.95-1.16; $p=0.33$ ). There were no significant differences in the numbers of deaths from cardiovascular causes (342 of those assigned to vitamin E vs. 328 of those assigned to placebo; $\mathrm{RR}=1.05,95 \% \mathrm{Cl}$ :
0.90-1.22), myocardial infarction (532 vs. 524; $R R=1.02,95 \% \mathrm{Cl}: 0.90-1.15)$, or stroke (209 vs. $180 ; \mathrm{RR}=1.17 ; 95 \% \mathrm{Cl}: 0.95-1.42)$. There were also no significant differences in the incidence of secondary cardiovascular outcomes or in death from any cause. There were no significant adverse effects of vitamin E [76]. Similarly, The Physicians' Health Study II was a randomized, double-blind, placebo-controlled factorial trial of vitamin $\mathrm{E}$ and vitamin C that began in 1997 and continued until its scheduled completion in 2007 [77]. There were 14,641 US male physicians enrolled, who were initially aged 50 years or older, including 754 (5.1\%) men with prevalent cardiovascular disease at randomization. Each individual received supplements of $400 \mathrm{IU}$ of vitamin E every other day and $500 \mathrm{mg}$ of vitamin $\mathrm{C}$ daily. The composite end point was comprised of nonfatal myocardial infarction, nonfatal stroke, and cardiovascular disease death [77]. During a mean follow-up of 8 years, there were 1245 confirmed major cardiovascular events; compared with placebo, vitamin $\mathrm{E}$ had no effect on the incidence of major cardiovascular events (both active and placebo vitamin $\mathrm{E}$ groups, 10.9 events per 1000 person-years; hazard ratio $(\mathrm{HR})=1.01,95 \% \mathrm{Cl}: 0.90-1.13, p=$ $0.86)$, as well as total myocardial infarction $(\mathrm{HR}=0.90,95 \% \mathrm{Cl}: 0.75-1.07, p=0.22)$, total stroke $(\mathrm{HR}=1.07,95 \% \mathrm{Cl}: 0.89-1.29, p=0.45)$, and cardiovascular mortality $(\mathrm{HR}=1.07,95 \% \mathrm{Cl}$ : $0.90-1.28, p=0.43)$; but vitamin $\mathrm{E}$ was associated with an increased risk of hemorrhagic stroke $(\mathrm{HR}=1.74,95 \% \mathrm{Cl}: 1.04-2.91, p=0.04)[77]$.

High-dose niacin (vitamin $B_{3}$ ) is used in the treatment of hyperlipidemia [78]. Randomized, double-blind, placebo-controlled investigations showed that sustained-released niacin decreases LDL-C, TC, and TG and raises HDL-C [79-81]. A multicenter, randomized, double-blind clinical trial enrolled 122 patients with confirmed diagnosis of primary dyslipidemia (LDL cholesterol > $4.14 \mathrm{mmol} / \mathrm{l}(160 \mathrm{mg} / \mathrm{dl})$ and triglycerides < $9 \mathrm{mmol} / \mathrm{l}(800 \mathrm{mg} / \mathrm{dl}))$ into 3 treatment groups: (1) Niaspan 1,000 mg/day; (2) Niaspan 2,000 mg/ day; and (3) placebo. The primary treatment endpoint was LDL-C level. This endpoint was not significantly affected by placebo ( $0.2 \%$ increase), but Niaspan decreased LDL-C by $5.8 \%$ (1,000 mg/day) and $14.6 \%(2,000 \mathrm{mg} /$ day $)(p<0.001)$ [79]. Likewise, with placebo there were significant changes in TC, triglycerides, lipoprotein(a), and apoprotein B, whereas both Niaspan 1,000 and 2,000 mg/day significantly $(p<0.001)$ decreased these parameters. In addition, both Niaspan groups showed significant $(p<0.001)$ increases in HDL-C $(17 \%$ and $23 \%$, respectively), including HDL subfractions. This trial demonstrated a cholesterol-modifying effect of Niaspan consistent with those 
reported for niacin, but demonstrated a better tolerance for flushing [79]. Another multicenter trial evaluated the safety and efficacy of escalating doses of Niaspan (from a dose of $375 \mathrm{mg}$ / day to $500-3,000 \mathrm{mg} /$ day in 25 weeks) and placebo in 131 patients with primary hyperlipidemia on the percent change from baseline in levels of LDL-C and apolipoprotein B. Significant decreases from baseline in levels of LDL-C and apolipoprotein B became apparent with the $500-\mathrm{mg} /$ day dose and were consistent at all subsequent doses ( $p \leq 0.05$ ), reaching $21 \%$ and $20 \%$, respectively, at the 3,000-mg/day dose [81]. Significant increases from baseline in levels of HDL-C became apparent with the 500-mg/day dose and were consistent at all subsequent doses $(p \leq 0.05)$, reaching $30 \%$ at the 3,000-mg dose. Significant decreases from baseline in triglycerides and lipoprotein(a) occurred at the 1,000-mg dose and were apparent at all subsequent doses ( $p \leq 0.05$ ), reaching 44\% and $26 \%$, respectively, at the 3,000-mg dose [81]. Previously available randomized clinical trial data assessing the clinical efficacy of niacin have been challenged by results from AIM-HIGH and HPS-2 THRIVE, which failed to demonstrate a reduction in CVD event incidence in patients with established CVD treated with niacin as an adjunct to intensive simvastatin therapy $[82,83]$.

Equol is produced by intestinal bacteria from isoflavone daidzein. Liu et al. in a randomized controlled trial examined the effect of whole soy (soy flour) and purified daidzein on cardiovascular biomarkers in prehypertensive postmenopausal women who were equol producers [84]. Two hundred seventy eligible women were randomized to either one of the three treatments: $40 \mathrm{~g}$ soy flour (whole soy group), $40 \mathrm{~g}$ low-fat milk powder $+63 \mathrm{mg}$ daidzein (daidzein group), or $40 \mathrm{~g}$ low-fat milk powder (placebo group) daily each for 6 months; after 6 months of treatment, serum LDL-C decreased by $7.95 \%$ (whole soy group) and $6.32 \%$ (daidzein group) compared to the placebo group [84].

Several studies have focused on the effects of calcium intake on serum lipid concentrations in postmenopausal women with dyslipidemia. In one trial, a total of 190 premenopausal women and 182 postmenopausal women with dyslipidemia were given $800 \mathrm{mg}$ calcium/day or a placebo for 2 years in a double-blind, randomized, placebo-controlled trial [85]. The change in TC in premenopausal women and postmenopausal women after calcium supplementation was $0.04 \pm 0.07 \mathrm{mmol} / \mathrm{l}$ compared with $0.61 \pm 0.21 \mathrm{mmol} / \mathrm{l}$, respectively, and there was a significant interaction effect between calcium supplementation and menopausal status on serum cholesterol concentrations (from baseline $5.56 \pm 0.65 \mathrm{mmol} / \mathrm{l}$ to 2 years 5.87 $\pm 0.71 \mathrm{mmol} / \mathrm{l} ; p<0.001$ ) [85]. In the prospective
Data from an Epidemiologic Study on the Insulin Resistance Syndrome study (DESIR) with 9 years of follow-up, in a large cohort drawn from the French general population, the consumption of dairy products and cheeses, as well as the density of calcium (defined as the amount of calcium ingested per 1,000 kcal) in the diet, were associated with a lower incidence of MetS and were also associated with a lower incidence of IFG or type 2 diabetes [86]. Although dairy products contain saturated fatty acids they can reduce the risk of cardiovascular disease. The objective of one study was to determine the early (7 days) and sustained (4 and 12 weeks) effects of adequate-dairy (AD) compared with low-dairy (LD) diets in subjects with metabolic syndrome [87]. Forty overweight and obese adults with metabolic syndrome were randomly assigned to receive AD (3.5 daily servings) or LD (< 0.5 daily servings) weight-maintenance diets for 12 weeks. The AD decreased malondialdehyde and oxidized LDL at 7 days (35\% and $11 \%$, respectively; $p<0.01$ ), with further decreases by 12 weeks [87]. Inflammatory markers were suppressed with intake of $A D$, with decreases in tumor necrosis factor- $\alpha$ (TNF- $\alpha$ ) at 7 days and further reductions through 12 weeks (35\%; $p<0.05)$; decreases in interleukin-6 (IL-6) (21\%; $p<0.02$ ) and monocyte chemoattractant protein 1 (14\% decrease at 4 weeks, $24 \%$ decrease at 12 weeks; $p<0.05$ ); and a corresponding $55 \%$ increase in adiponectin at 12 weeks $(p<0.01)$. The LD exerted no effect on oxidative or inflammatory markers. Diet had no effect on body weight; however, AD significantly reduced waist circumference and trunk fat ( $p<0.01$ for both), while LD exerted no effect [87]. An higher intake of dairy products rich in calcium inhibits the generation of reactive oxygen species, thus relieving oxidative stress, and may help reduce the risk of developing MetS. Adipose tissue reactive oxygen species (ROS) production and NADPH oxidase and plasma malondialdehyde (MDA) were reduced by the high-Ca diet ( $p<0.001)$ compared with the basal diet, and ROS and MDA were further decreased by the high-dairy diet $(p<0.001)$ [88]. The high-Ca and -dairy diets also resulted in suppression of adipose tissue TNF- $\alpha$ and IL-6 $(p=0.001)$ compared with the basal diet, whereas an inverse pattern was noted for adiponectin and IL-15 ( $p=0.002)$. Consequently, a high-dairy eucaloric diet resulted a reduction of $29 \%(p<0.01)$ in C-reactive protein. Adiponectin decreased by $8 \%$ in subjects fed the eucaloric high-dairy diet $(p=0.003)$ and $18 \%$ in those fed the hypocaloric high-dairy diet $(p<0.05)$ [88].

Rosenblat et al. evaluated the effects of $\mathrm{PJ}$ (50 $\mathrm{ml}$ per day for 3 months) given to ten diabetic patients and ten placebo patients on glycemic parameters and oxidative stress in their serum and 
macrophages [89]. The PJ consumption did not affect serum glucose, cholesterol or triglyceride levels, but it resulted in a significant reduction in serum lipid peroxides by $56 \%$, in cellular peroxides by $71 \%$, and in oxidized LDL (Ox-LDL) by $37 \%$. The PJ consumption by diabetic patients did not worsen diabetic parameters, but rather resulted in anti-oxidative effects on serum and macrophages, which could impact atherogenesis in these patients [89].

It has been shown that zinc deficiency increases the risk of glucose intolerance, diabetes, insulin resistance, atherosclerosis, and CHD [90]. In diabetic patients given 12 weeks of therapy with zinc at a concentration of $100 \mathrm{mg} /$ day, TC and triglyceride levels decreased and HDL-C levels increased. These results will require validation in a larger placebo-controlled trial [90].

\section{Effects of nutraceuticals on vascular damage}

\section{Prothrombotic and proinflammatory states}

Guerrero-Romero et al. examined the relationship between MetS, hypomagnesemia, inflammation, and oxidative stress in patients with MetS (84 women and 63 men) compared with healthy control subjects [91]. Multivariate analysis showed a strong association between MetS and hypomagnesemia $(\mathrm{OR}=1.9 ; 95 \% \mathrm{Cl}: 1.3-7.1)$, inflammation $(\mathrm{OR}=1.7 ; 95 \% \mathrm{Cl}: 1.4-8.4)$, and oxidative stress $(\mathrm{OR}=1.4 ; 95 \% \mathrm{Cl}: 0.9-12.6)$. The interaction of inflammation and oxidative stress is related to and increases the risk for MetS, whereas serum magnesium levels and MetS are independently associated [91].

Some studies suggest that omega-3 polyunsaturated fatty acids reduce the damage caused by oxidative stress and restore free radical homeostasis [92, 93]. Free radicals adversely alter lipids, proteins, and DNA and trigger a number of human diseases. A balance between free radicals and antioxidants is necessary for proper physiological function. If free radicals overwhelm the body's ability to regulate them, a condition known as oxidative stress ensues [92]. The human body has several mechanisms to counteract oxidative stress by producing antioxidants, which are either naturally produced in situ, or externally supplied through foods and/or supplements [91]. The mechanism of action is not completely understood, but the effect of omega-3 supplementation involves an increase in glutathione (GSH) plasma levels and in the concentration of antioxidant enzymes (glutathione peroxidase and copper/zinc superoxide dismutase) and a reduction in the concentration of malonic dialdehyde [94, 95].

Vitamin $C$ is a scavenger antioxidant and decreases peroxyl radical formation [96]. In addition to blocking lipid peroxidation by trapping peroxyl radicals in the aqueous phase, vitamin $C$ helps to regenerate $\alpha$-tocopherol from $\alpha$-tocopherol radicals in membranes and lipoproteins, and also raises intracellular glutathione levels, thus playing an important role in protein thiol group protection against oxidation [97], and helps normalize endothelial vasodilator function in patients with heart failure by increasing the availability of NO [98]. High doses of vitamin $\mathrm{C}$ have also been associated with decreased levels of NO production by endothelial cells. The overloading of ascorbic acid (AA) in cells can change the oxidative-reduction status inside cells. This could decrease the availability of NO, through the formation of peroxynitrite. NO can move very rapidly through membranes, and hence the reactions of inactivation may also occur in the extracellular space between cells. Suppression of NO generation appears to be one of the mechanisms by which AA mediates angiostatic effects [99]. A study reported that vitamin C slowed the progression of atherosclerosis in men and women older than 55 years [100]. British researchers found that higher blood levels of vitamin C were directly and inversely related to death from all causes and specifically death from ischemic heart disease in both men and women [101]. The researchers strongly advocated modest consumption of fruits and vegetables, since their results suggested that the equivalent of one extra serving of vitamin $\mathrm{C}$ rich food reduced the risk of death by $20 \%$ [102]. Vitamin C at daily dosages of $500 \mathrm{mg}$ has been shown to increase red cell glutathione by 50\% [103]. Glutathione is not only a major antioxidant responsible for inhibiting lipid peroxidation, but is also a key agent responsible for stabilizing immune function [96].

Observational data suggest a link between menaquinone ( $M K$, vitamin $\mathrm{K}_{2}$ ) intake and cardiovascular (CV) health. MK intervention trials with vascular endpoints are lacking. Knapen et al. investigated long-term effects of MK-7 (180 $\mu \mathrm{g}$ MenaQ7/day) supplementation on arterial stiffness in a double-blind, placebo-controlled trial in healthy postmenopausal women $(n=244)$ who received either placebo $(n=124)$ or MK-7 $(n=120)$ for 3 years [104]. Circulating desphospho-uncarboxylated matrix Gla-protein (dp-ucMGP) as well as acute phase markers IL-6, hs-CRP, TNF- $\alpha$ and markers for endothelial dysfunction (vascular cell adhesion molecule-1 (VCAM-1) and E-selectin), and advanced glycation end products (AGEs) were measured [105]. At baseline dp-ucMGP was associated with cIMT, diameter, carotid-femoral and carotid-radial pulse wave velocity (cfPWV), and with the mean z-scores of acute phase markers (APM score) and of markers for endothelial dysfunction (EDF score); after 3 years 
of MK-7 supplementation, cfPWV and the stiffness index $\beta$ significantly decreased in the total group, whereas distension, compliance, distensibility, Young's modulus, and the local carotid PWV (CPWV) improved in women having a baseline stiffness index $\beta$ above the median of 10.8. MK-7 reduced dp-ucMGP by $50 \%$ compared to placebo, but did not influence the markers for acute phase and endothelial dysfunction [105].

Matrix metalloproteinases (MMPs) are important in atherogenesis [106]. Endothelial dysfunction represents an alteration of normal endothelial function, which involves the loss of some structural features and/or function. The endothelium can be considered a true autocrine and paracrine organ, capable of secreting, in response to a large variety of signals, a number of chemical mediators [106]. The relationship between MMPs and traditional risk factors for cardiovascular disease (CVD) and any influence of lifestyle changes are largely unknown. Furenes et al. studied the effects of 3 years of dietary counseling and/or n-3 PUFA supplementation ( $2.4 \mathrm{~g} /$ day) on the levels of MMP-9, tissue inhibitor of metalloproteinase (TIMP-1) and pregnancy-associated plasma protein (PAPP-A) in a population of elderly male smokers at high risk of CVD ( $n=563$, age $70 \pm 6$ years) and subjects with previous acute myocardial infarction (AMI) [107]. Smokers had significantly higher levels of MMP-9 ( $p<0.0001)$, and TIMP-1 levels were lower in subjects with previous AMI $(p=0.021)$. MMP-9 was significantly correlated with LDL-C and inversely with HDL-C (both $p<0.0001)$. Significant reductions in MMP-9 and PAPP-A levels after 36 months were found in all study groups, but without between-group differences [107]. They further explored the association between these markers and different disease entities, CIMT and traditional risk factors for CVD. Smokers had significantly higher levels of MMP-9 $(p<0.0001)$, and TIMP-1 levels were lower in subjects with previous AMI $(p=0.021)$. MMP-9 was significantly correlated with LDL-C and inversely with HDL-C (both $p<0.0001)$. Significant reductions in MMP-9 and PAPP-A levels after 36 months were found in all study groups, but without between-group differences [107].

Black rice and its pigment fraction have shown anti-atherogenic activities in several animal models, but whether there are beneficial effects in humans remains unknown. Wang et al. investigated the influence of black rice pigment fraction (BRF) supplementation on selected cardiovascular risk factors in patients with CHD [108]. Sixty patients with CHD aged 45-75 years were randomly divided into two groups. In the test group, the diet was supplemented with $10 \mathrm{~g}$ of BRF derived from black rice for 6 months, while in the place- bo group, the diet was supplemented with $10 \mathrm{~g}$ of white rice pigment fraction (WRF) derived from white rice [108]. At baseline, plasma antioxidant status and the levels of inflammatory biomarkers and other measured variables were similar between the two groups. After 6 months' intervention, compared to WRF supplementation, BRF supplementation greatly enhanced plasma total antioxidant capacity (TAC) (BRF group from baseline $11.1 \pm 3.53$ to 6 months $12.4 \pm 4.24$, change $1.29 \pm 2.96$; WRF group from baseline $10.3 \pm 2.73$ to 6 months $9.70 \pm 2.30$, change $-0.61 \pm 1.69$; $p=0.003)$, significantly reduced plasma levels of soluble vascular cell adhesion molecule-1 (sVCAM-1) (BRF group from baseline $1367 \pm 756$ to 6 months $993 \pm 532$, change $-373 \pm 492$; WRF group from baseline $1236 \pm 548$ to 6 months $1208 \pm 690$, change $-28.2 \pm 691 ; p=0.03$ ), soluble CD40 ligand (sCD4OL) (BRF group from baseline $8.36 \pm 4.09$ to 6 months $5.73 \pm 2.37$, change -2.63 \pm 3.27 ; WRF group from baseline $8.25 \pm 4.53$ to 6 months $8.85 \pm 4.73$, change $0.60 \pm 4.43$; $p=0.002$ ) and hs-CRP (BRF group from baseline $3.82 \pm 1.82$ to 6 months $2.55 \pm 1.66$, change -1.27 \pm 1.66 ; WRF group from baseline $3.58 \pm 1.71$ to 6 months $3.82 \pm 1.96$, change $0.24 \pm 1.99 ; p=$ 0.002 ) in the test group. No significant changes were observed in plasma total superoxide dismutase (T-SOD) activity, lipid levels or cIMT between the two groups [108].

\section{Carotid intima-media thickness and other non-invasive vascular parameters}

Increased cIMT predicts risk for CV events [109]. In fact, increased CIMT is considered a manifestation of subclinical atherosclerosis, and it was included in the list of conditions of organ damage in the European guidelines of arterial hypertension [110] and in the European guidelines for Cardiovascular Prevention and Rehabilitation [111]. The ease of performing the measurement and the reproducibility of the method make CIMT an attractive biomarker, potentially useful as a therapeutic target in patients at increased CV risk [100].

Aviram et al. studied the effects of PJ in patients with carotid atherosclerosis (CAS), high blood pressure and changes in oxidative stress [112]. Their results suggest that consumption of PJ reduces cIMT by up to $30 \%$ and systolic blood pressure by $12 \%$ and these effects may be related to the powerful antioxidant properties of polyphenols [112].

Ethyl alcohol in small quantities, without taking into account type of beverage, may provide protection against cardiovascular or cerebrovascular disease [113]. Red wine has antioxidant activity through an effect of polyphenol flavonoids [113]. Resveratrol, as an isolated substance, is now being 
studied as a potential drug for cardioprotection [114]. In a small survey conducted in the Netherlands, the use of dietary bioflavonoids, phenolic acids and quercetin showed a reduced incidence of myocardial infarction and sudden death [115].

Quercetin-rich black tea, apples and onions were the best foods evaluated, because they contain polyphenols in amounts similar to those found in red grapes used for wine production and grape juice, and consumption of black tea in the short and long term has been shown to reverse endothelial vasomotor dysfunction in patients with CAD [116].

Vegetarian diets have been associated with atherosclerosis protection, with healthier atherosclerosis risk profiles, as well as lower prevalence of, and mortality from, ischemic heart disease and stroke [105]. Vitamin $B_{12}$ deficiency is highly prevalent in vegetarians; this can be partially alleviated by taking dairy/egg products in lactoovo-vegetarians. Vascular studies have demonstrated impaired arterial endothelial function and increased cIMT as atherosclerosis surrogates in such metabolic vitamin $B_{12}$ deficient populations [117]. Regular monitoring of vitamin $B_{12}$ status is thus potentially beneficial for early detection and treatment of metabolic vitamin $B_{12}$ deficiency in vegans, and possibly for prevention of atherosclerosis-related diseases [117].

The B-PROOF study is a double-blind, randomized controlled trial, including 2919 elderly aged at least 65 years, with hyperhomocysteinemia (12-50 $\mu \mathrm{mol} / \mathrm{l})$, treated with B-vitamins (500 $\mu \mathrm{g}$ vitamin $B_{12}$ and $400 \mu \mathrm{g}$ folic acid) or placebo for 2 years [118]. In a subgroup $(n=569)$, the effect of B-vitamins on pulse wave velocity (PWV) was investigated as a measurement of arterial stiffness; to measure atherosclerosis, CIMT measures were used. Compared to placebo, B-vitamin supplementation lowered serum homocysteine by $3.6 \mu \mathrm{mol} / \mathrm{l}$ $(p<0.001)$ [118]. Analysis of covariance showed no effect of supplementation on PWV levels, and this was not different for patients without increased arterial stiffness at baseline. Furthermore, no effect on CIMT was observed [119]. In the Study of the Effectiveness of Additional Reductions in Cholesterol and Homocysteine (SEARCH) trial, a double-blind randomized trial (intention to treat), 12,064 subjects with a history of myocardial infarction were either currently on or had a clear indication for statin therapy, and had a TC concentration of at least 3-5 mmol// [120]. Among patients given $2 \mathrm{mg}$ of folic acid and $1 \mathrm{mg}$ of vitamin $B_{12}$ daily versus placebo, there was no discernible cardiovascular benefit to vitamin therapy. Vegetarians are more vascular-healthy, but those with a subnormal vitamin $B_{12}$ status have impaired arterial endothelial function and increased intima-media thickness. In a double-blind, placebo-controlled, randomized crossover study [121], 50 healthy vegetarians (vegetarian diet for at least 6 years) were recruited. Vitamin $B_{12}(500 \mu \mathrm{g} /$ day $)$ or identical placebo was given for 12 weeks with 10 weeks of placebo washout before crossover $(n=43)$, and then open label vitamin $B_{12}$ for an additional 24 weeks $(n=41)$. Vitamin $B_{12}$ supplementation significantly increased serum vitamin $B_{12}$ levels $(p<0.0001)$ and lowered plasma homocysteine $(p<0.05)$ [121]. After vitamin $B_{12}$ supplementation but not placebo, significant improvement of flow-mediated dilation of the brachial artery (FMD) $(6.3 \pm 1.8 \%$ to $6.9 \pm 1.9 \% ; p<0.0001)$ and of CIMT $(0.69 \pm 0.09 \mathrm{~mm}$ to $0.67 \pm 0.09 \mathrm{~mm}$, $p<0.05)$ were observed, with further improvement in FMD (to $7.4 \pm 1.7 \%$; $p<0.0001$ ) and IMT (to $0.65 \pm 0.09 \mathrm{~mm} ; p<0.001$ ) after 24 weeks of open label vitamin $B_{12}$ [121]. There were no significant changes in blood pressures or lipid profiles. On multivariate analysis, changes in $B_{12}$ $(\beta=0.25 ; p=0.02)$ but not homocysteine were related to changes in FMD $(R=0.32 ; F$ value $=3.19$; $p=0.028$ ) [121].

Hodis et al. determined whether reduction of plasma total homocysteine (tHcy) levels with $B$ vitamin supplementation reduces subclinical atherosclerosis progression [122]. This double-blind clinical trial recruited 506 participants 40 to 89 years of age with an initial tHcy $>8.5 \mu \mathrm{mol} / \mathrm{l}$ without diabetes and cardiovascular disease; patients were randomized to highdose vitamin B supplementation ( $5 \mathrm{mg}$ folic acid $+0.4 \mathrm{mg}$ vitamin $B_{12}+50 \mathrm{mg}$ vitamin $B_{6}$ ) or matching placebo for 3.1 years [122]. Although the overall cIMT progression rate was lower with vitamin B supplementation than with placebo, statistically significant between-group differences were not found ( $p=0.31$ ) [122]. However, among subjects with baseline tHcy $\geq 9.1 \mu \mathrm{mol} / \mathrm{l}$, those randomized to vitamin B supplementation had a statistically significantly lower average rate of cIMT progression compared with placebo $(p=0.02)$; among subjects with a baseline tHcy $<9.1 \mu \mathrm{mol} / \mathrm{l}$, there was no significant treatment effect $(p=0.02)$ [99]. Vitamin B supplementation had no effect on progression of aortic or coronary artery calcification overall or within subgroups [122].

Vitamin $D$ receptors have been found in the vascular smooth muscle [123] and cardiomyocytes [124]. There are data to suggest that low levels of 25-hydroxyvitamin-D may be associated with accelerated development of cardiovascular disease [125]. Supplementation of calcium (Ca) and vitamin D for the prevention of osteoporosis is frequently found. Recent re-analyses of clinical trials observed a higher risk of myocardial infarction and stroke in subjects taking Ca (+ vitamin D) 
supplements, although the underlying mechanisms are not clear. The National Osteoporosis Foundation and the American Society for Preventive Cardiology adopt the position that calcium intake from food and supplements that does not exceed the tolerable upper intake level (defined by the National Academy of Medicine as 2000 to $2500 \mathrm{mg}$ (day) should be considered safe from a cardiovascular standpoint [126]. Thiele et al. analyzed the associations between Ca and vitamin D supplementation as well as serum concentrations of $\mathrm{Ca}$ and 25-hydroxyvitamin $\mathrm{D}(25(\mathrm{OH}) \mathrm{D})$ and subclinical cardiovascular disease (CVD) phenotypes, namely intima-media thickness, ankle-brachial index $(\mathrm{ABI})$, intermittent claudication, and atrial fibrillation (AF) [127]. Data of 1601 participants aged $50-81$ years of the population-based cross-sectional Cooperative Health Research in the Region of Augsburg (KORA) F4 study in Germany were analyzed. Regular Ca supplementation showed a significant positive association with the presence of AF after multivariable adjustment $(\mathrm{OR}=3.89 ; 95 \% \mathrm{Cl}: 1.28-11.81)$ [127]. Higher serum $25(\mathrm{OH}) \mathrm{D}$ concentrations were independently associated with a lower prevalence of asymptomatic peripheral arterial disease as assessed by $A B I$ measurements $(\beta=0.007 ; p=0.01)$. No other significant associations between supplementation or serum concentrations of $\mathrm{Ca}$ or vitamin $\mathrm{D}$ and CVD phenotypes were identified [127]. The change in CIMT in premenopausal women and postmenopausal women after calcium supplementation was $0.0238 \pm 0.0348$ compared with $0.0615 \pm 0.134$ $\mathrm{mm}(p=0.017)$, respectively [125].

An observational pilot sub-study of the San Valentino epidemiological cardiovascular study [128] included 1363 subjects aged 45-60 without any conventional risk factors who had non-stenosing atherosclerotic plaques $(<50 \%)$ in at least one carotid or common femoral bifurcation, allocated into 6 groups: controls (group 1) - management was based on education, exercise, diet and lifestyle changes, and this same management plan was used in all groups; group 2 - Pycnogenol $50 \mathrm{mg} /$ day (Pycnogenol is the registered trade name for a special extract from the outer bark of the French maritime pine Pinus pinaster ssp. atlantica and it is highly concentrated in flavonoids, the primary constituents being procyanidins, taxifolin, ferulic acid, catechin, and caffeic acid) [129]; group 3 - Pycnogenol 100 mg/day; group 4 - aspirin $100 \mathrm{mg} /$ day or ticlopidine $250 \mathrm{mg} /$ day if intolerant to aspirin; group 5 - aspirin $100 \mathrm{mg} /$ day and Pycnogenol 100 mg/day; group 6 - Pycnogenol $100 \mathrm{mg} /$ day plus TECA (total triterpenic fraction of Centella asiatica) $100 \mathrm{mg} /$ day [128]. There was a 6 monthly follow-up up to 30 months. Plaque progression was assessed using the ultrasonic ar- terial score based on the arterial wall morphology and the number of plaques that progressed from the non-stenotic to the stenotic group. A secondary endpoint was to evaluate the changes in oxidative stress at baseline and at 30 months. The ultrasonic score increased significantly in groups 1,2 and 4 but not in groups 3, 5 and 6, suggesting a beneficial effect of Pycnogenol $100 \mathrm{mg}$. The percentage of plaques that progressed from class IV to class $V$ was $8.4 \%$ in group 2; $5.3 \%$ in group 3; $4 \%$ in group 5 and $1.1 \%$ in group $6(p<0.0001)$ compared with $16.6 \%$ in group 4 (aspirin) and $21.3 \%$ in the control group, suggesting a beneficial effect of Pycnogenol [128]. The lowest rate of progression was in group 6 (Pycnogenol plus TECA). The results justify a large randomized controlled study to demonstrate the efficacy of the combined Pycnogenol and TECA prophylactic therapy in subclinical atherosclerosis [128].

Zou et al. evaluated the effects of lutein and lycopene supplementation on CIMT in subjects with subclinical atherosclerosis [130]. A total of 144 subjects aged 45-68 years were recruited from local communities. All the subjects were randomly assigned to receive $20 \mathrm{mg}$ lutein/day $(n=48), 20 \mathrm{mg}$ lutein/day $+20 \mathrm{mg}$ lycopene/day $(n=48)$ or placebo $(n=48)$ for 12 months. Serum lutein concentrations increased significantly from 0.34 to $1.96 \mu \mathrm{mol} / \mathrm{l}$ in the lutein group $(p<0.001)$ and from 0.35 to $1.66 \mu \mathrm{mol} / \mathrm{l}$ in the combination group $(p<0.001)$. Similarly, serum lycopene concentrations increased significantly from 0.18 to $0.71 \mu \mathrm{mol} / \mathrm{l}$ in the combination group at 12 months ( $p<0.001$ ), whereas no significant change was observed in the placebo group [130]. The mean values of CIMT decreased significantly by $0.035 \mathrm{~mm}(p=0.042)$ and $0.073 \mathrm{~mm}$ $(p<0.001)$ in the lutein and combination groups at 12 months, respectively [130]. The change in CIMT was inversely associated with the increase in serum lutein concentrations $(p<0.05)$ in both the active treatment groups and with the increase in serum lycopene concentrations $(\beta=-0.342$, $p=0.031)$ in the combination group. Lutein and lycopene supplementation significantly increased the serum concentrations of lutein and lycopene, with a decrease in CIMT being associated with both concentrations. In addition, the combination of lutein and lycopene supplementation was more effective than lutein alone for protection against the development of CIMT in Chinese subjects with subclinical atherosclerosis, and further studies are needed to confirm whether synergistic effects of lutein and lycopene exist [130].

Although epidemiological and experimental studies suggest that dietary intake of soy may be cardioprotective, use of isoflavone soy protein (ISP) supplementation as a primary preventive 
Table I. Effects of nutraceuticals on metabolic syndrome components

\begin{tabular}{|c|c|c|c|}
\hline \multirow[t]{2}{*}{ Nutraceuticals } & \multicolumn{3}{|c|}{ Effects on metabolic syndrome components } \\
\hline & Abdominal obesity & Blood pressure & Glycemic and lipid metabolism \\
\hline Black rice & & & No effect on plasma lipids [108] \\
\hline Calcium & $\downarrow$ Adiponectin [88] & & $\begin{array}{c}\downarrow \text { Cholesterol levels [85] } \\
\downarrow \text { IFG or diabetes [86] }\end{array}$ \\
\hline Chokeberry & & & $\begin{array}{c}\downarrow \text { Cholesterol [32] } \\
\downarrow \text { Triglycerides [32] } \\
\downarrow \text { LDL-C [32] } \\
\text { No effect on glycemic profile [32] }\end{array}$ \\
\hline $\begin{array}{l}\text { Citrus } \\
\text { bergamia }\end{array}$ & & & $\begin{array}{c}\downarrow \text { Cholesterol [17] } \\
\downarrow \text { Triglycerides [17] } \\
\downarrow \downarrow \text { LDL-C [17] } \\
\quad \uparrow \text { HDL-C [17] }\end{array}$ \\
\hline Curcumin & $\begin{array}{c}\downarrow \text { Body weight [31, 32] } \\
\downarrow \text { Body fat [31, 32] } \\
\downarrow \text { Waistline [31, 32] } \\
\downarrow \text { Hip circumference [31] } \\
\quad \downarrow \text { BMI }[31,32]\end{array}$ & & $\begin{array}{l}\downarrow \text { Fasting glucose [32] } \\
\downarrow \text { Total cholesterol [32] }\end{array}$ \\
\hline Equol & & & $\downarrow$ LDL-C [84] \\
\hline Garlic & & $\begin{array}{c}\downarrow \text { Systolic and diastolic blood } \\
\text { pressure [42] }\end{array}$ & \\
\hline $\begin{array}{l}\text { GIMM (inulin, } \\
\beta \text {-glucan, } \\
\text { blueberry } \\
\text { polyphenols) }\end{array}$ & $\downarrow$ Ghrelin concentrations [49] & & $\begin{array}{l}\uparrow \text { Blood glucose tolerance [49] } \\
\text { No effect on lipid profile [49] }\end{array}$ \\
\hline Ginseng & $\downarrow$ Body weight [57] & & $\begin{array}{c}\downarrow \text { Fasting glucose [57] } \\
\downarrow \mathrm{HbA}_{1 \mathrm{c}}[57] \\
\uparrow \text { Insulin [60-64, 66] } \\
\downarrow \text { Cholesterol [58] } \\
\downarrow \text { LDL-C [58] } \\
\text { Suppression of HMG-CoA } \\
\text { reductase [58] } \\
\text { Suppression of cholesterol } \\
7 \alpha \text {-hydroxylase [58] }\end{array}$ \\
\hline Green tea & $\begin{array}{c}\downarrow \text { Body fat, body weight } \\
{[21,22]} \\
\downarrow \text { Waist circumference [22] }\end{array}$ & $\downarrow$ Blood pressure $[21,38]$ & $\begin{array}{c}\downarrow \text { Cholesterol [38] } \\
\downarrow \text { Triglycerides [38] } \\
\quad \downarrow \text { LDL-C [38] } \\
\quad \uparrow \text { HDL-C [38] }\end{array}$ \\
\hline Mulberry & $\downarrow$ Adiponectin [52] & & $\begin{array}{c}\downarrow \text { Cholesterol [52] } \\
\downarrow \text { Triglycerides [52] } \\
\downarrow \text { LDL-C [52] } \\
\uparrow \text { HDL-C [52] }\end{array}$ \\
\hline $\begin{array}{l}\text { Omega-3 } \\
\text { fatty acids }\end{array}$ & $\begin{array}{c}\text { EPA and DHA } \downarrow \text { adipose tissue } \\
\text { mass [24] }\end{array}$ & $\begin{array}{c}\text { Beneficial effects of ALA, EPA } \\
\text { and DHA on systolic } \\
\text { and diastolic blood pressure } \\
{[44,45]}\end{array}$ & $\begin{array}{c}\downarrow \text { Cholesterol }[65,66] \\
\downarrow \text { Triglycerides }[65,66] \\
\downarrow \text { LDL-C }[65,66,107] \\
\uparrow \operatorname{HDL}-C[65,107,133]\end{array}$ \\
\hline Phosphorus & & $\downarrow$ Blood pressure [48] & \\
\hline Pomegranate & & $\begin{array}{c}\downarrow \text { Blood pressure [35-37] } \\
\downarrow \text { Systolic blood pressure [112] }\end{array}$ & $\begin{array}{c}\text { No effects on serum glucose, } \\
\text { cholesterol and triglyceride } \\
\text { levels [89] }\end{array}$ \\
\hline Quercetin & & $\begin{array}{l}\text { Its effects on blood pressure } \\
\text { have not been conclusive [46] } \\
\downarrow \text { Systolic and diastolic blood } \\
\text { pressure [47] }\end{array}$ & \\
\hline
\end{tabular}


A.M. Patti, K. Al-Rasadi, R.V. Giglio, D. Nikolic, C. Mannina, G. Castellino, R. Chianetta, M. Banach, A.F.G. Cicero, G. Lippi, G. Montalto, M. Rizzo, P.P. Toth

Table I. Cont.

\begin{tabular}{|c|c|c|c|}
\hline \multirow[t]{2}{*}{ Nutraceuticals } & \multicolumn{3}{|c|}{ Effects on metabolic syndrome components } \\
\hline & Abdominal obesity & Blood pressure & Glycemic and lipid metabolism \\
\hline Resveratrol & $\begin{array}{c}\text { No effect on BMI, body weight, } \\
\text { fat mass and abdominal fat } \\
\text { distribution [28] }\end{array}$ & & $\begin{array}{c}\text { Does not reduce plasma levels } \\
\text { of } T C, L D L-C \text { and } T G[50]\end{array}$ \\
\hline Soy & & & $\downarrow$ LDL-C [84] \\
\hline $\begin{array}{l}\text { Vitamin } \mathrm{B}_{3} \\
\text { (Niacin) }\end{array}$ & & & $\begin{array}{c}\downarrow \text { Cholesterol [79-81] } \\
\downarrow \text { Triglycerides [79-81] } \\
\downarrow \downarrow \text { LDL-C [79-81] } \\
\downarrow \text { Apoprotein B [79-81] } \\
\uparrow \text { HDL-C [79-81] }\end{array}$ \\
\hline Vitamin $\mathrm{B}_{12}$ & & & $\downarrow$ LDL-C [120] \\
\hline Vitamin D & $\begin{array}{l}\text { No significant change in } \\
\text { plasma concentrations of } \\
\text { adiponectin and leptin [29] } \\
\downarrow \text { Body weight, waist } \\
\text { circumference and BMI [30] }\end{array}$ & $\downarrow$ Systolic blood pressure [30] & $\downarrow$ HOMA-IR [30] \\
\hline Zinc & & & $\begin{array}{c}\downarrow \text { Cholesterol [90] } \\
\downarrow \text { Triglycerides [90] } \\
\uparrow \text { HDL-C [90] } \\
\downarrow \text { Glucose intolerance and } \\
\text { diabetes [90] }\end{array}$ \\
\hline
\end{tabular}

therapy remains unexplored. Hodis et al. determined whether ISP reduces subclinical atherosclerosis assessed as cIMT progression [131]. In a double-blind, placebo-controlled trial, 350 postmenopausal women 45 to 92 years of age without diabetes and cardiovascular disease were randomized to 2 evenly divided daily doses of $25 \mathrm{~g}$ soy protein containing $91 \mathrm{mg}$ aglycon isoflavone equivalents or placebo for 2.7 years [131]. Overall, the mean $(95 \% \mathrm{Cl}) \mathrm{CIMT}$ progression rate was $4.77(3.39-6.16) \mu \mathrm{m} / \mathrm{year}$ in the ISP group and $5.68(4.30-7.06) \mu \mathrm{m} /$ year in the placebo group. Although cIMT progression was reduced on average by $16 \%$ in the ISP group relative to the placebo group, this treatment effect was not statistically significant $(p=0.36)$ [131]. Among the subgroup of women who were randomized within 5 years of menopause, ISP participants had on average a $68 \%$ lower cIMT progression rate than placebo participants 2.16 ( -1.10 to 5.43$)$ vs. 6.79 (3.56-10.01) $\mu \mathrm{m} /$ year $(p=0.05)$. The ISP supplementation had a null effect on women who were $>5$ years beyond menopause when randomized. There were no major adverse events from ISP supplementation [131].

Observational studies have reported inverse associations between adherence to the Mediterranean diet (MedDiet) and atherosclerotic disease. The Primary Prevention of Cardiovascular Disease with a Mediterranean Diet (PREDIMED) group tested the effect of two types of MedDiet on progression of subclinical carotid atheroscle- rosis [132]. The group randomized 187 high-cardiovascular-risk asymptomatic subjects (51\% women, mean age 67 years) to three treatment arms: MedDiet with supplemental virgin olive oil (VOO), $n=66$; MedDiet with supplemental nuts, $n=59$; and control diet, $n=62$ [132]. After 1 year, overall, no significant between-group differences in IMT progression were observed. However, a significant interaction $(p=0.03)$ between baseline IMT and treatment effect was apparent [132]. Among participants with baseline IMT $\geq 0.9 \mathrm{~mm}$, 1-year IMT changes versus control showed significant differences of $-0.079 \mathrm{~mm}(95 \% \mathrm{Cl}:-0.145$ to $-0.012)$ for the MedDiet with VOO and $-0.072 \mathrm{~mm}$ $(-0.140$ to -0.004$)$ for the MedDiet with nuts. No IMT changes occurred in any intervention group among participants with lower baseline IMT values $(<0.9 \mathrm{~mm})$. MedDiets enhanced with VOO or nuts were not effective in inducing ultrasonographic regression of carotid atherosclerosis after 1-year intervention [132]. However, they were effective among subjects with elevated baseline IMT, suggesting that subclinical atherosclerosis may respond to dietary intervention within a relatively short time frame only among subjects with a high initial atherosclerotic burden [132].

A randomized study targeted a comparison of the effect of 3-year diet counseling or omega-3 polyunsaturated fatty acid (PUFA) supplementation $(2.4 \mathrm{~g} /$ day) on the progression of atherosclerosis in carotid arteries and on finger pulse wave propagation [133]. Altogether, 563 elderly men 
Table II. Effects of nutraceuticals on vascular damage

\begin{tabular}{|c|c|c|}
\hline \multirow[t]{2}{*}{ Nutraceuticals } & \multicolumn{2}{|c|}{ Effects on vascular damage } \\
\hline & Prothrombotic and inflammatory states & Vascular parameters \\
\hline Black rice & $\begin{aligned} \text { Enhances plasma total antioxidant capacity [108] } \\
\\
\downarrow \text { sVCAM-1 [108] } \\
\downarrow \text { sCD4OL [108] } \\
\text { No effect on T-SOD [108] }\end{aligned}$ & $\downarrow$ cIMT [108] \\
\hline Calcium & & $\begin{array}{c}\downarrow \text { ROS [88] } \\
\downarrow \text { NADPH oxidase [88] } \\
\downarrow \text { MDA [88] } \\
\downarrow \text { TNF- } \alpha[88] \\
\downarrow \text { IL-6 [88] }\end{array}$ \\
\hline Citrus bergamia & & $\downarrow$ cIMT [17] \\
\hline Curcumin & $\begin{array}{l}\text { No effect on parameters, including oxidative } \\
\text { stress }(\mathrm{GSH}, \mathrm{LOOH})[32]\end{array}$ & \\
\hline Green tea & $\begin{array}{c}\text { Inhibition of the expression of inducible nitric } \\
\text { oxide synthase [19] } \\
\uparrow \text { Levels of glutathione in the blood and } \\
\text { plasma total antioxidant capacity [58] }\end{array}$ & \\
\hline $\begin{array}{l}\text { Lutein and } \\
\text { lycopene }\end{array}$ & & $\downarrow$ cIMT [130] \\
\hline Magnesium & $\begin{array}{c}\downarrow \text { Inflammation [77] } \\
\downarrow \text { Oxidative stress [91] }\end{array}$ & \\
\hline Olive oil & & No reduction of cIMT [132] \\
\hline $\begin{array}{l}\text { Omega-3 fatty } \\
\text { acids }\end{array}$ & $\begin{array}{l}\downarrow \text { GSH }[94,95] \\
\uparrow \text { MDA }[94,95] \\
\downarrow \text { MMP-9 }[107] \\
\downarrow \text { PAPP-A [107] } \\
\downarrow \text { TIMP-1 }[119]\end{array}$ & 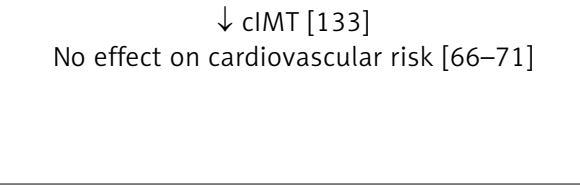 \\
\hline $\begin{array}{l}\text { Pinus pinaster } \\
\text { ssp. atlantica }\end{array}$ & & $\downarrow$ Reduction of plaque [128] \\
\hline Pomegranate & $\downarrow$ Oxidative stress [89] & $\downarrow$ cIMT [112] \\
\hline Quercetin & & $\begin{array}{l}\text { Antioxidant effects in cardiovascular disease } \\
\qquad[46]\end{array}$ \\
\hline Resveratrol & $\begin{array}{l}\text { Significant positive effect on inflammatory } \\
\text { markers [28] }\end{array}$ & \\
\hline Vitamin $B_{12}$ & & $\begin{array}{l}\text { No effects on cIMT or pulse wave velocity [118] } \\
\qquad \text { cIMT [120-122] } \\
\text { } \text { FMD [121] } \\
\downarrow \text { ABI [127] }\end{array}$ \\
\hline Vitamin C & $\begin{array}{c}\downarrow \text { Peroxyl radical formation [96] } \\
\downarrow \text { NO production by endothelial cells [99] } \\
\uparrow \text { Red cell glutathione [103] }\end{array}$ & \\
\hline Vitamin $\mathrm{E}$ & $\begin{array}{c}\text { Blocks the chain reaction of lipid peroxidation } \\
\text { by scavenging intermediate peroxyl radicals } \\
\text { [75] }\end{array}$ & $\begin{array}{l}\text { No significant differences in the numbers of } \\
\text { deaths from cardiovascular causes }[76,77]\end{array}$ \\
\hline $\begin{array}{l}\text { Vitamin } \mathrm{K}_{2} \\
\text { (menaquinone) }\end{array}$ & No effect on the markers for acute phase [105] & $\begin{array}{c}\downarrow \text { cfPWV [100] } \\
\downarrow \text { stiffness index } \beta \text { [105] } \\
\text { No effect on endothelial dysfunction [105] }\end{array}$ \\
\hline
\end{tabular}

with long-standing hyperlipidemia were randomized to four groups: controls (no dietary counseling and placebo); dietary counseling (and placebo); omega-3 PUFA supplementation (no dietary counseling); dietary counseling and omega-3 PUFA supplementation. In the diet only group, the CIMT increase $(0.929 \mathrm{~mm}$ to $0.967 \mathrm{~mm}$ ) was significantly less than in the control group $(0.909 \mathrm{~mm}$ to $0.977 \mathrm{~mm})(p=0.018)$. Significant increases in carotid plaques score and plaques area were observed in all four groups, but without between-group differences [133]. Changes in cIMT 
and in HDL-C were negatively correlated (adjusted $p<0.001$ ). Pulse wave propagation time decreased significantly in the control group $(206 \mathrm{~ms}$ to $198 \mathrm{~ms} ; p=0.002$ ), reflecting reduced arterial elasticity. In the group receiving omega-3 PUFA only, pulse wave propagation time increased significantly when compared with the control group $(p=0.013)$ [133].

\section{Conclusions}

Nutraceuticals represent an alternative form of medicine compared with the healing traditions that in the recent past were not part of standard medical education. However, more and more people are seeking nutraceutical remedies for their health care needs. Although most of the nutraceutical therapies are relatively harmless, there are many unknowns. As this review demonstrates, there are numerous molecular and cellular dynamics that may be beneficially impacted by many of the components in nutraceuticals. There is much yet to be investigated, characterized, and learned.

The use of nutraceuticals for the treatment of cardiovascular disease is the subject of criticism. Nutraceuticals are a challenge for the education of many cardiovascular physicians, with many positive effects considered to be placebo effects. Some of many existing nutraceutical compounds could be used as integrators in a daily diet thanks to their easy availability and to their beneficial properties, such as in polyphenols, omega-3 fatty acids, macroelements and vitamins used as non-pharmacologic treatment. Natural products can also be useful in the therapy with metabolic syndrome and statin intolerance; especially MetS might increase the risk of statin intolerance - via liver dysfunction/steatosis $[134,135]$. Use of food supplements in MetS has a beneficial effect on the individual components [136-138]. This results in improved blood pressure [139], blood glucose and lipids [11, 13, 140, 141]. Vitamin D supplementation correlates with significant improvements in plasma concentrations of adiponectin and leptin. Inulin, $\beta$-glucan, blueberry anthocyanins, and blueberry polyphenols reduce plasma ghrelin concentrations and improve blood glucose tolerance. The critical importance of phosphorus in cellular structure and function could have profound effects on blood pressure regulation through its role in plasma membrane structure. Magnesium plays a role in regulating vascular tone and endothelial function. Ginseng supplementation lowers cholesterol and LDL-C with the suppression of $\beta$-hydroxy- $\beta$-methylglutaryl-CoA reductase. White mulberry extract has a significant impact on the changes in the LDL-C subfractions (Table I). Adherence to a low-calorie diet supported with supplements promotes weight loss and improves the markers of oxidative stress. Bergamot juice (neoeriocitrin, neohesperidin, naringin) has an effect on metabolic parameters, including plasma lipids, atherogenic lipoproteins and subclinical atherosclerosis. Vitamin E blocks the chain reaction of lipid peroxidation by scavenging intermediate peroxyl radicals, though it has not yet shown cardiovascular benefit in prospective randomized trials. Quercetin has antioxidant effects since it protects against $\mathrm{H}_{2} \mathrm{O}_{2}$-induced lipid peroxidation and reduces the cytokine-induced cell-surface expression of vascular cell adhesion molecule-1. Black rice and its pigment fraction have shown anti-atherogenic activities. There are ongoing studies (REDUCE-IT and STRENGTH) that will help to more firmly establish the role of omega-3 fish oils for cardiovascular protection (Table II). It is possible that food supplements may reduce the risk of cardiovascular disease in patients with MetS, though many prospective randomized trials will have to be performed in order to more reliably establish this.

Further studies are needed to evaluate the efficacy and safety of these natural compounds in patients at high cardiovascular risk, because there are still conflicting data on some of these and cardio-metabolic prevention (for example omega-3 and resveratrol). Adequate education of clinicians and patients regarding the medicinal properties of nutraceuticals must be provided regionally and globally to ensure both consumer safety and to prevent overstating their clinical efficacy.

\section{Conflict of interest}

The authors declare no conflict of interest.

\section{References}

1. Expert Panel on Detection, Evaluation, and Treatment of High Blood Cholesterol in Adults Executive Summary of the Third Report of the National Cholesterol Education Program (NCEP) Expert Panel on Detection, Evaluation, and Treatment of High Blood Cholesterol in Adults (Adult Treatment Panel III). JAMA 2001; 285: 2486-97.

2. Mikhailidis DP, Elisaf M, Rizzo M, et al. “European panel on low density lipoprotein (LDL) subclasses": a statement on the pathophysiology, atherogenicity and clinical significance of LDL subclasses: executive summary. Curr Vasc Pharmacol 2011; 9: 531-2.

3. Mikhailidis DP, Elisaf M, Rizzo M, et al. "European panel on low density lipoprotein (LDL) subclasses": a statement on the pathophysiology, atherogenicity and clinical significance of LDL subclasses. Curr Vasc Pharmacol 2011; 9: 533-71.

4. Kassi E, Pervanidou P, Kaltsas G, et al. Metabolic syndrome: definitions and controversies. BMC Med 2011; 5: 9-48.

5. Rabe K, Lehrke M, Parhofer KG, et al. Adipokines and insulin resistance. Mol Med 2008; 14: 741-51. 
6. Mansego ML, Redon J, Martinez-Hervas S, et al. Different impacts of cardiovascular risk factors on oxidative stress. Int J Mol Sci 2011; 12: 6146-63.

7. Stern MP, Williams K, González-Villalpando C, et al. Does the metabolic syndrome improve identification of individuals at risk of type 2 diabetes and/or cardiovascular disease? Diabetes Care 2004; 27: 2676-81.

8. Kaur J. A comprehensive review on metabolic syndrome. Cardiol Res Pract 2014; 2014: 943162

9. Pandey KB, Rizvi SI. Plant polyphenols as dietary antioxidants in human health and disease. Oxid Med Cell Longev 2009; 2: 270-8.

10. Alissa EM, Ferns GA. Functional foods and nutraceuticals in the primary prevention of cardiovascular diseases. J Nutr Metab 2012; 2012: 569486.

11. Barrios V, Escobar C, Cicero AF, et al. A nutraceutical approach (Armolipid Plus) to reduce total and LDL cholesterol in individuals with mild to moderate dyslipidemia: review of the clinical evidence. Atheroscler Suppl 2017; 24: 1-15.

12. Ooi EM, Watts GF, Ng TW, et al. Effect of dietary fatty acids on human lipoprotein metabolism: a comprehensive update. Nutrients 2015; 7: 4416-25.

13. Sahebkar A, Serban MC, Gluba-Brzózka A, et al. Lipid-modifying effects of nutraceuticals: an evidence-based approach. Nutrition 2016; 32: 1179-92.

14. Abete I, Goyenechea E, Zulet MA, et al. Obesity and metabolic syndrome: potential benefit from specific nutritional components. Nutr Metab Cardiovasc Dis 2011; 21 Suppl 2: B1-15.

15. Giglio RV, Patti AM, Nikolic D, et al. The effect of bergamot on dyslipidemia. Phytomedicine 2016; 23: 1175-81.

16. Rizzo M, Giglio RV, Nikolic D, et al. Effects of chitosan on plasma lipids and lipoproteins: a 4-month prospective pilot study. Angiology 2014; 65: 538-42.

17. Toth PP, Patti AM, Nikolic D, et al. Bergamot reduces plasma lipids, atherogenic small dense LDL, and subclinical atherosclerosis in subjects with moderate hypercholesterolemia: a 6 months prospective sudy. Front Pharmacol 2016; 6: 299.

18. Patti AM, Al-Rasadi K, Katsiki N, et al. Effect of a natural supplement containing curcuma longa, guggul, and chlorogenic acid in patients with metabolic syndrome. Angiology 2015; 66: 856-61.

19. Chacko SM, Thambi PT, Kuttan R, et al. Beneficial effects of green tea: a literature review. Chin Med 2010; 5: 13.

20. Serban C, Sahebkar A, Antal D, et al. Effects of supplementation with green tea catechins on plasma C-reactive protein concentrations: a systematic review and meta-analysis of randomized controlled trials. Nutrition 2015; 31: 1061-71.

21. Basu A, Sanchez K, Leyva MJ, et al. Green tea supplementation affects body weight, lipids, and lipid peroxidation in obese subjects with metabolic syndrome. J Am Coll Nutr 2010; 29: 31-40.

22. Mousavi A, Vafa M, Neyestani T, et al. The effects of green tea consumption on metabolic and anthropometric indices in patients with type 2 diabetes. J Res Med Sci 2013; 18: 1080-6.

23. Simopoulos AP. The importance of the ratio of omega-6/omega-3 essential fatty acids. Biomed Pharmacother 2002; 56: 365-79.

24. Poudyal H, Panchal SK, Diwan V, et al. Omega-3 fatty acids and metabolic syndrome: effects and emerging mechanisms of action. Prog Lipid Res 2011; 50: 37287.
25. Du S, Jin J, Fang W, et al. Does fish oil have an anti-obesity effect in overweight/obese adults? A meta-analysis of randomized controlled trials. PLoS One 2015; 10 : e0142652.

26. Jurgoński A, Juśkiewicz J, Zduńczyk Z. Ingestion of black chokeberry fruit extract leads to intestinal and systemic changes in a rat model of prediabetes and hyperlipidemia. Plant Foods Hum Nutr 2008; 63: 176-82.

27. Kowalczyk E, Fijałkowski P, Kura $M$, et al. The influence of anthocyanins from Aronia melanocarpa on selected parameters of oxidative stress and microelements contents in men with hypercholesterolemia. Pol Merkur Lekarski 2005; 19: 651-3.

28. Christenson J, Whitby SJ, Mellor D, et al. The effects of resveratrol supplementation in overweight and obese humans: a systematic review of randomized trials. Metab Syndr Relat Disord 2016; 14: 323-33.

29. Dinca M, Serban MC, Sahebkar A, et al.; Lipid Blood Pressure Meta-analysis Collaboration LBPMC Group. Does vitamin D supplementation alter plasma adipokines concentrations? A systematic review and meta-analysis of randomized controlled trials. Pharmacol Res 2016; 107: 360-71.

30. Nimitphong H, Samittarucksa R, Saetung $S$, et al. The effect of vitamin D supplementation on metabolic phenotypes in Thais with prediabetes. J Med Assoc Thai 2015; 98: 1169-78.

31. Di Pierro F, Bressan A, Ranaldi D, et al. Potential role of bioavailable curcumin in weight loss and omental adipose tissue decrease: preliminary data of a randomized, controlled trial in overweight people with metabolic syndrome. Preliminary study. Eur Rev Med Pharmacol Sci 2015; 19: 4195-202.

32. Langley P. Why a pomegranate? BMJ 2000; 321: 1153-4.

33. Ben Nasr C, Ayed N, Metche M. Quantitative determination of the polyphenolic content of pomegranate peel. Z Lebensm Unters Forsch 1996; 203: 374-8.

34. Gil MI, Tomás-Barberán FA, Hess-Pierce B, et al. Antioxidant activity of pomegranate juice and its relationship with phenolic composition and processing. J Agric Food Chem 2000; 48: 4581-9.

35. Stowe CB. The effects of pomegranate juice consumption on blood pressure and cardiovascular health. Complement Ther Clin Pract 2011; 17: 113-5.

36. Aviram M, Dornfeld L. Pomegranate juice consumption inhibits serum angiotensin converting enzyme activity and reduces systolic blood pressure. Atherosclerosis 2001; 158: 195-8.

37. Galley HF, Thornton J, Howdle PD, et al. Combination oral antioxidant supplementation reduces blood pressure. Clin Sci (Lond) 1997; 92: 361-5.

38. Bogdanski P, Suliburska J, Szulinska M, et al. Green tea extract reduces blood pressure, inflammatory biomarkers, and oxidative stress and improves parameters associated with insulin resistance in obese, hypertensive patients. Nutr Res 2012; 32: 421-7.

39. Mikaili P, Maadirad S, Moloudizargari M, et al. Therapeutic uses and pharmacological properties of garlic, shallot, and their biologically active compounds. Iran J Basic Med Sci 2013; 16: 1031-48.

40. Sahebkar A, Serban C, Ursoniu S, et al. Effect of garlic on plasma lipoprotein(a) concentrations: a systematic review and meta analysis of randomized controlled clinical trials. Nutrition 2016; 32: 33-40.

41. Ried K, Fakler P. Potential of garlic (Allium sativum) in lowering high blood pressure: mechanisms of action and clinical relevance. Integr Blood Press Control 2014; 7: 71-82. 
42. Gómez-Arbeláez D, Lahera V, Oubiña P, et al. Aged garlic extract improves adiponectin levels in subjects with metabolic syndrome: a double-blind, placebo-controlled, randomized, crossover study. Mediators Inflamm 2013; 2013: 285795.

43. Bayan L, Koulivand PH, Gorji A. Garlic: a review of potential therapeutic effects. Avicenna J Phytomed 2014; 4: 1-14.

44. Houston $M$. The role of nutrition and nutraceutical supplements in the treatment of hypertension. World J Cardiol 2014; 6: 38-66.

45. Zanetti M, Grillo A, Losurdo P, et al. Omega-3 polyunsaturated fatty acids: structural and functional effects on the vascular wall. Biomed Res Int 2015; 2015 791978.

46. Kleemann R, Verschuren L, Morrison M, et al. Anti-inflammatory, anti-proliferative and anti-atherosclerotic effects of quercetin in human in vitro and in vivo models. Atherosclerosis 2011; 218: 44-52.

47. Serban MC, Sahebkar A, Zanchetti A, et al. Lipid and Blood Pressure Meta-analysis Collaboration (LBPMC) Group. Effects of quercetin on blood pressure: a systematic review and meta-analysis of randomized controlled trials. J Am Heart Assoc 2016; 5: e002713.

48. Elliott P, Kesteloot H, Appel L), et al.; INTERMAP Cooperative Research Group. Dietary phosphorus and blood pressure: international study of macro- and micro-nutrients and blood pressure. Hypertension 2008; 51: 669-75.

49. Rebello CJ, Burton J, Heiman M, et al. Gastrointestinal microbiome modulator improves glucose tolerance in overweight and obese subjects: a randomized controlled pilot trial. J Diabetes Complications 2015; 29: 1272-6.

50. Broncel M, Koziróg-Kołacińska M, Andryskowski G, et al. Effect of anthocyanins from Aronia melanocarpa on blood pressure, concentration of endothelin-1 and lipids in patients with metabolic syndrome. Pol Merkur Lekarski 2007; 23: 116-9.

51. Sicińska P, Pytel E, Maćczak A, et al. The use of various diet supplements in metabolic syndrome. Postepy Hig Med Dosw (Online) 2015; 69: 25-33.

52. Kojima Y, Kimura T, Nakagawa K, et al. Effects of mulberry leaf extract rich in 1-deoxynojirimycin on blood lipid profiles in humans. J Clin Biochem Nutr 2010; 47: 155-61.

53. Scichilone N, Rizzo M, Benfante A, et al. Serum low density lipoprotein subclasses in asthma. Respir Med 2013; 107: 1866-72.

54. Berneis K, Rizzo M, Berthold HK, et al. Ezetimibe alone or in combination with simvastatin increases small dense low-density lipoproteins in healthy men: a randomized trial. Eur Heart J 2010; 31: 1633-9.

55. Wang A, Wang CZ, Wu JA, et al. Determination of major ginsenosides in Panax quinquefolius (American ginseng) using high-performance liquid chromatography. Phytochem Anal 2005; 16: 272-7.

56. Yin J, Zhang $\mathrm{H}$, Ye J. Traditional Chinese medicine in treatment of metabolic syndrome. Endocr Metab Immune Disord Drug Targets 2008; 8: 99-111.

57. Sotaniemi EA, Haapakoski E, Rautio A. Ginseng therapy in non-insulin-dependent diabetic patients. Diabetes Care 1995; 18: 1373-5.

58. Qureshi AA, Abuirmeileh N, Din ZZ, et al. Suppression of cholesterogenesis and reduction of LDL cholesterol by dietary ginseng and its fractions in chicken liver. Atherosclerosis 1983; 48: 81-94.
59. Post SM, Groenendijk M, van der Hoogt CC, et al. Cholesterol 7alpha-hydroxylase deficiency in mice on an APOE*3-Leiden background increases hepatic ABCA1 mRNA expression and HDL-cholesterol. Arterioscler Thromb Vasc Biol 2006; 26: 2724-30.

60. Waki I, Kyo H, Yasuda M, et al. Effects of a hypoglycemic component of ginseng radix on insulin biosynthesis in normal and diabetic animals. J Pharmacobiodyn 1982; 5: 547-54.

61. Lee WK, Kao ST, Liu IM, et al. Increase of insulin secretion by ginsenoside Rh2 to lower plasma glucose in Wistar rats. Clin Exp Pharmacol Physiol 2006; 33 : 27-32.

62. Su CF, Cheng JT, Liu IM. Increase of acetylcholine release by Panax ginseng root enhances insulin secretion in Wistar rats. Neurosci Lett 2007; 412: 101-4.

63. Luo JZ, Luo L. American ginseng stimulates insulin production and prevents apoptosis through regulation of uncoupling protein-2 in cultured beta cells. Evid Based Complement Alternat Med 2006; 3: 365-72.

64. Hasegawa H, Matsumiya S, Murakami C, et al. Interactions of ginseng extract, ginseng separated fractions, and some triterpenoid saponins with glucose transporters in sheep erythrocytes. Planta Med 1994; 60: 153-7.

65. Siri-Tarino PW, Sun Q, Hu FB, et al. Saturated fatty acids and risk of coronary heart disease: modulation by replacement nutrients. Curr Atheroscler Rep 2010; 12: 384-90.

66. Ballantyne CM, Bays HE, Kastelein JJ, et al. Efficacy and safety of eicosapentaenoic acid ethyl ester (AMR101) therapy in statin-treated patients with persistent high triglycerides (from the ANCHOR study). Am J Cardiol 2012; 110: 984-92.

67. No authors listed. Dietary supplementation with n-3 polyunsaturated fatty acids and vitamin E after myocardial infarction: results of the GISSI-Prevenzione trial. Gruppo Italiano per lo Studio della Sopravvivenza nell'Infarto miocardico. Lancet 1999; 354: 447-55.

68. Yokoyama M, Origasa H, Matsuzaki M, et al. Effects of eicosapentaenoic acid on major coronary events in hypercholesterolaemic patients (JELIS): a randomised open-label, blinded endpoint analysis. Lancet 2007; 369: 1090-8.

69. Clinicaltrials.gov. A Study of AMR101 to Evaluate Its Ability to Reduce Cardiovascular Events in High Risk Patients with Hypertriglyceridemia and on Statin. The Primary Objective is to Evaluate the Effect of $4 \mathrm{~g} /$ Day AMR101 for Preventing the Occurrence of a First Major Cardiovascular Event. (REDUCE-IT) Clinicaltrials.gov; 2014. Available from: https://clinicaltrials.gov/ct2/ show/NCT01492361.

70. Clinicaltrials.gov. Outcomes Study to Assess Statin Residual Risk Reduction with Epanova in High CV Risk Patients with Hypertriglyceridemia (STRENGTH) 2015. Available from: https://clinicaltrials.gov/ct2/show/ NCT02104817.

71. Toth PP. Triglyceride-rich lipoproteins as a causal factor for cardiovascular disease. Vasc Health Risk Manag 2016; 12: 171-83.

72. Walz CP, Barry AR, Koshman SL. Omega-3 polyunsaturated fatty acid supplementation in the prevention of cardiovascular disease. Can Pharm J 2016; 149: 166-73.

73. Kwak SM, Myung SK, Lee YJ, et al. Efficacy of omega-3 fatty acid supplements (eicosapentaenoic acid and docosahexaenoic acid) in the secondary prevention of cardiovascular disease: a meta-analysis of random- 
ized, double-blind, placebo-controlled trials. Arch Intern Med 2012; 172: 686-94.

74. Rizos EC, Ntzani EE, Bika E, et al. Association between omega-3 fatty acid supplementation and risk of major cardiovascular disease events: a systematic review and meta-analysis. JAMA 2012; 308: 1024-33.

75. Pryor WA. Vitamin E and heart disease: basic science to clinical intervention trials. Free Radic Biol Med 2000; 28: 141-64.

76. Yusuf S, Dagenais G, Pogue J, et al. Vitamin E supplementation and cardiovascular events in high-risk patients. The Heart Outcomes Prevention Evaluation Study Investigators. N Engl J Med 2000; 342: 154-60.

77. Sesso HD, Buring JE, Christen WG, et al. Vitamins E and $C$ in the prevention of cardiovascular disease in men: the Physicians' Health Study II randomized controlled trial. JAMA 2008; 300: 2123-33.

78. Goel H, Dunbar RL. Niacin alternatives for dyslipid emia: fool's gold or gold mine? Part II: novel niacin mimetics. Curr Atheroscler Rep 2016; 18: 17.

79. Morgan JM, Capuzzi DM, Guyton JR. A new extend ed-release niacin (Niaspan): efficacy, tolerability, and safety in hypercholesterolemic patients. Am J Cardiol 1998; 82: 29U-34U; discussion 39U-41U.

80. Goldberg A, Alagona P Jr, Capuzzi DM, et al. Multiple-dose efficacy and safety of an extended-release form of niacin in the management of hyperlipidemia. Am J Cardiol 2000; 85: 1100-5.

81. Goldberg AC. Clinical trial experience with extended-release niacin (Niaspan): dose-escalation study. Am J Cardiol 1998; 82: 35U-8U; discussion 39U-41U.

82. The AIM-HIGH Investigators. Niacin in patients with low $\mathrm{HDL}$ cholesterol levels receiving intensive statin therapy. N Engl J Med 2011; 365: 2255-67.

83. HPS2-THRIVE Collaborative Group. Landray MJ Haynes R, Hopewell JC, et al. Effects of extended-release niacin with laropiprant in high-risk patients. N Engl J Med 2014; 371: 203-12.

84. Liu ZM, Ho SC, Chen YM, et al. Whole soy, but not purified daidzein, had a favorable effect on improvement of cardiovascular risks: a 6-month randomized, double-blind, and placebo-controlled trial in equol-producing postmenopausal women. Mol Nutr Food Res 2014; 58: 709-17.

85. Li S, Na L, Li Y, et al. Long-term calcium supplementation may have adverse effects on serum cholesterol and carotid intima-media thickness in postmenopausal women: a double-blind, randomized, placebo-controlled trial. Am J Clin Nutr 2013; 98: 1353-9.

86. Fumeron F, Lamri A, Abi Khalil C, et al. Dairy consumption and the incidence of hyperglycemia and the metabolic syndrome: results from a French prospective study. Data from the Epidemiological Study on the Insulin Resistance Syndrome (DESIR). Diabetes Care 2011; 34: 813-7.

87. Stancliffe RA, Thorpe T, Zemel MB. Dairy attenuates oxidative and inflammatory stress in metabolic syndrome. Am J Clin Nutr 2011; 94: 422-30.

88. Zemel MB, Sun X. Dietary calcium and dairy products modulate oxidative and inflammatory stress in mice and humans. J Nutr 2008; 138: 1047-52.

89. Rosenblat M, Hayek T, Aviram M. Anti-oxidative effects of pomegranate juice (PJ) consumption by diabetic patients on serum and on macrophages. Atherosclerosis 2006; 187: 363-71

90. Partida-Hernández G, Arreola F, Fenton B, et al. Effect of zinc replacement on lipids and lipoproteins in type 2 diabetic patients. Biomed Pharmacother 2006; 60: 161-8.

91. Guerrero-Romero F, Rodríguez-Morán M. Hypomagnesemia, oxidative stress, inflammation, and metabolic syndrome. Diabetes Metab Res Rev 2006; 22: 471-6.

92. Lobo V, Patil A, Phatak A, et al. Free radicals, antioxidants and functional foods: impact on human health. Pharmacogn Rev 2010; 4: 118-26.

93. Pham-Huy LA, He H, Pham-Huy C. Free radicals, antioxidants in disease and health. Int J Biomed Sci 2008; 4: 89-96.

94. Romieu I, Garcia-Esteban R, Sunyer J, et al. The effect of supplementation with omega-3 polyunsaturated fatty acids on markers of oxidative stress in elderly exposed to PM(2.5). Environ Health Perspect 2008; 116: 1237-42.

95. Tayyebi-Khosroshahi H, Houshyar J, Tabrizi A, et al. Effect of omega-3 fatty acid on oxidative stress in patients on hemodialysis. Iran J Kidney Dis 2010; 4: 322-6.

96. Rahman K. Studies on free radicals, antioxidants, and co-factors. Clin Interv Aging 2007; 2: 219-36.

97. Naziroğlu M, Butterworth PJ. Protective effects of moderate exercise with dietary vitamin $\mathrm{C}$ and $\mathrm{E}$ on blood antioxidative defense mechanism in rats with streptozotocin-induced diabetes. Can J Appl Physiol 2005; 30: $172-85$.

98. Frishman WH. Nutriceuticals as treatments for cardiovascular disease. Heart Dis 1999; 1: 51.

99. Mikirova NA, Ichim TE, Riordan NH. Anti-angiogenic effect of high doses of ascorbic acid. J Transl Med 2008; 6: 50.

100. Vasan RS. Biomarkers of cardiovascular disease: molecular basis and practical considerations. Circulation 2006; 113: 2335-62.

101. Khaw KT, Bingham S, Welch A, et al. Relation between plasma ascorbic acid and mortality in men and women in EPIC-Norfolk prospective study: a prospective population study. European Prospective Investigation into Cancer and Nutrition. Lancet 2001; 357: 657-63.

102. Willcox BJ, Curb JD, Rodriguez BL. Antioxidants in cardiovascular health and disease: key lessons from epidemiologic studies. Am J Cardiol 2008; 101: 75D-86D.

103. Johnston CS, Meyer CG, Srilakshmi JC. Vitamin C elevates red blood cell glutathione in healthy adults. Am J Clin Nutr 1993; 58: 103-5.

104. Knapen MH, Braam LA, Drummen NE, et al. Menaquinone-7 supplementation improves arterial stiffness in healthy postmenopausal women. A double-blind randomised clinical trial. Thromb Haemost 2015; 113: 1135-44.

105. Huang T, Yang B, Zheng J, et al. Cardiovascular disease mortality and cancer incidence in vegetarians: a metaanalysis and systematic review. Ann Nutr Metab 2012; 60: 233-40.

106. Hermes O, Schlage P, auf dem Keller U. Wound degradomics - current status and future perspectives. Biol Chem 2011; 392: 949-54.

107. Furenes EB, Seljeflot I, Solheim S, et al. Long-term influence of diet and/or omega-3 fatty acids on matrix metalloproteinase- 9 and pregnancy-associated plasma protein-A in men at high risk of coronary heart disease. Scand I Clin Lab Invest 2008; 68: 177-84.

108. Wang Q, Han P, Zhang M, et al. Supplementation of black rice pigment fraction improves antioxidant and anti-inflammatory status in patients with coronary heart disease. Asia Pac J Clin Nutr 2007; 16 Suppl 1: 295-301. 
109. O'Leary DH, Polak JF, Kronmal RA, et al. Carotid-artery intima and media thickness as a risk factor for myocardial infarction and stroke in older adults. Cardiovascular Health Study Collaborative Research Group. N Engl J Med 1999; 340: 14-22.

110. Mancia G, De Backer G, Dominiczak A, et al. The Task Force for the Management of Arterial Hypertension of the European Society of Hypertension (ESH) and of the European Society of Cardiology (ESC). Eur Heart 2007; 28: 1462-536.

111. Graham I, Atar D, Borch-Johnsen K, et al. European Association for Cardiovascular Prevention and Rehabilitation (EACPR). European guidelines on cardiovascular disease prevention in clinical practice: executive summary. Eur J Cardiovasc Prev Rehabil 2007; 14: 1-40.

112. Aviram M, Rosenblat M, Gaitini D, et al. Pomegranate juice consumption for 3 years by patients with carotid artery stenosis reduces common carotid intima-media thickness, blood pressure and LDL oxidation. Clin Nutr 2004; 23: 423-33.

113. Frishman WH, Del Vecchio A, Sanal S, et al. Cardiovascular manifestations of subtance abuse: part 2: alcohol, amphetamines, heroin, cannabis, and caffeine. Heart Dis 2003; 5: 253-71.

114. Sahebkar A, Serban C, Ursoniu S, et al. Lipid and Blood Pressure Meta-analysis Collaboration Group. Lack of efficacy of resveratrol on C-reactive protein and selected cardiovascular risk factors. Results from a sys tematic review and meta-analysis of randomized controlled trials. Int J Cardiol 2015; 189: 47-55.

115. Hertog MG, Feskens EJ, Hollman PC, et al. Dietary antioxidant flavonoids and risk of coronary heart disease: the Zutphen Elderly Study. Lancet 1993; 342: 1007-11.

116. Duffy SJ, Keaney JF Jr, Holbrook M, et al. Short- and long-term black tea consumption reverses endothelial dysfunction in patients with coronary artery disease. Circulation 2001; 104: 151-6.

117. Kwok T, Chook P, Tam L, et al. Vascular dysfunction in Chinese vegetarians: an apparent paradox? J Am Coll Cardiol 2005; 46: 1957-8.

118. van Dijk SC, Enneman AW, Swart KM, et al. Effects of 2-year vitamin B12 and folic acid supplementation in hyperhomocysteinemic elderly on arterial stiffness and cardiovascular outcomes within the B-PROOF trial. J Hypertens 2015; 33: 1897-906.

119. Tong TY, Wareham NJ, Khaw KT, et al. Prospective association of the Mediterranean diet with cardiovascular disease incidence and mortality and its population impact in a non-Mediterranean population: the EPIC-Norfolk study. BMC Med 2016; 14: 135

120. Study of the Effectiveness of Additional Reductions in Cholesterol and Homocysteine (SEARCH) Collaborative Group. Intensive lowering of LDL cholesterol with $80 \mathrm{mg}$ versus $20 \mathrm{mg}$ simvastatin daily in 12,064 survivors of myocardial infarction: a double-blind randomised trial. Lancet 2010; 376: 1658-69.

121. Kwok T, Chook P, Qiao M, et al. Vitamin B-12 supplementation improves arterial function in vegetarians with subnormal vitamin B-12 status. J Nutr Health Aging 2012; 16: 569-73.

122. Hodis HN, Mack WJ, Dustin L, et al.; BVAIT Research Group. High-dose B vitamin supplementation and progression of subclinical atherosclerosis: a randomized controlled trial. Stroke 2009; 40: 730-6.

123. Somjen D, Weisman Y, Kohen F, et al. 25-hydroxyvitamin D3-1alpha-hydroxylase is expressed in human vascular smooth muscle cells and is upregulated by parathyroid hormone and estrogenic compounds. Circulation 2005; 111: 1666-71.

124. Holick MF. High prevalence of vitamin D inadequacy and implications for health. Mayo Clin Proc 2006; 81: 353-73.

125. Wang TJ, Pencina MJ, Booth SL, et al. Vitamin D deficiency and risk of cardiovascular disease. Circulation 2008; 117: 503-11.

126. Kopecky SL, Bauer DC, Gulati M, et al. Lack of evidence linking calcium with or without vitamin D supplementation to cardiovascular disease in generally healthy adults: a clinical guideline from the National Osteoporosis Foundation and the American Society for Preventive Cardiology. Ann Intern Med 2016; 165: 867-8.

127. Thiele I, Linseisen J, Meisinger C, et al. Associations between calcium and vitamin D supplement use as well as their serum concentrations and subclinical cardiovascular disease phenotypes. Atherosclerosis 2015; 241: 743-51.

128. Belcaro G, Dugall M, Hosoi M, et al. Pycnogenol ${ }^{\circledR}$ and Centella Asiatica for asymptomatic atherosclerosis progression. Int Angiol 2014; 33: 20-6.

129. Lee $\mathrm{HH}$, Kim KJ, Lee $\mathrm{OH}$, et al. Effect of pycnogenol on glucose transport in mature 3T3-L1 adipocytes. Phytother Res 2010; 24: 1242-9.

130. Zou ZY, Xu XR, Lin XM, et al. Effects of lutein and lycopene on carotid intima-media thickness in Chinese subjects with subclinical atherosclerosis: a randomised, double-blind, placebo-controlled trial. $\mathrm{Br}$ J Nutr 2014; 111: 474-80.

131. Hodis HN, Mack WJ, Kono N, et al.; Women's Isoflavone Soy Health Research Group. Isoflavone soy protein supplementation and atherosclerosis progression in healthy postmenopausal women: a randomized controlled trial. Stroke 2011; 42: 3168-75.

132. Murie-Fernandez M, Irimia P, Toledo E, et al. PREDIMED Investigators. Carotid intima-media thickness changes with Mediterranean diet: a randomized trial (PREDIMED-Navarra). Atherosclerosis 2011; 219: 158-62.

133. Hjerkinn EM, Abdelnoor M, Breivik L, et al. Effect of diet or very long chain omega-3 fatty acids on progression of atherosclerosis, evaluated by carotid plaques, intima-media thickness and by pulse wave propagation in elderly men with hypercholesterolaemia. Eur J Cardiovasc Prev Rehabil 2006; 13: 325-33.

134. Serban MC, Colantonio LD, Manthripragada AD, et al. Statin intolerance and risk of coronary heart events and all-cause mortality following. J Am Coll Cardiol 2017; 69: 1386-95.

135. Banach M, Rizzo M, Toth PP, et al. Statin intolerance an attempt at a unified definition. Position paper from an International Lipid Expert Panel. Arch Med Sci 2015; 11: 1-23.

136. Serban MC, Sahebkar A, Mikhailidis DP, et al. Impact of L-carnitine on plasma lipoprotein(a) concentrations: a systematic review and meta-analysis of randomized controlled trials. Sci Rep 2016; 6: 19188.

137. Cicero AF, Tartagni E, Ertek S. Nutraceuticals for metabolic syndrome management: from laboratory to benchside. Curr Vasc Pharmacol 2014; 12: 565-71.

138. Serban MC, Sahebkar A, Dragan S, et al. A systematic review and meta-analysis of the impact of Spirulina supplementation on plasma lipid concentrations. Clin Nutr 2016; 35: 842-51.

139. Serban C, Sahebkar A, Ursoniu S, et al. Effect of sour tea (Hibiscus sabdariffa L.) on arterial hypertension a systematic review. J Hypertens 2015; 33: 1119-27. 
140. Ursoniu S, Sahebkar A, Andrica F, et al. Lipid and Blood Pressure Meta-analysis Collaboration (LBPMC) Group. Effects of flaxseed supplements on blood pressure: a systematic review and meta-analysis of controlled clinical trial. Clin Nutr 2016; 35: 615-2.

141. Ursoniu S, Sahebkar A, Serban MC, et al. Lipid profile and glucose changes after supplementation with astaxanthin: a systematic review and meta-analysis of randomized controlled trials. Arch Med Sci 2015; 11 : 253-66. 